J Comp Neurol. 2017 December 15; 525(18): 3787-3808. doi:10.1002/cne.24294.

\title{
Distinct Projection Targets Define Subpopulations of Mouse Brainstem Vagal Neurons that Express the Autism-Associated MET Receptor Tyrosine Kinase
}

\author{
Anna Kamitakahara ${ }^{1}$, Hsiao-Huei $\mathrm{Wu}^{4}$, and Pat Levitt ${ }^{1,2,3}$ \\ ${ }^{1}$ Program in Developmental Neurogenetics, Institute for the Developing Mind, The Saban Resarch \\ Institute, Children's Hospital Los Angeles, Los Angeles, CA 90027 \\ ${ }^{2}$ Department of Pediatrics, Keck School of Medicine of University of Southern California, Los \\ Angeles, CA 90027 \\ ${ }^{3}$ University of Southern California Program in Neuroscience, Los Angeles, CA 90089 \\ ${ }^{4}$ Keck School of Medicine of University of Southern California, Los Angeles, CA 90089
}

\section{Abstract}

Detailed anatomical tracing and mapping of the viscerotopic organization of the vagal motor nuclei has provided insight into autonomic function in health and disease. To further define specific cellular identities, we paired information based on visceral connectivity with a cell-type specific marker of a subpopulation of neurons in the dorsal motor nucleus of the vagus (DMV) and nucleus ambiguus (nAmb) that express the autism-associated MET receptor tyrosine kinase. As gastrointestinal disturbances are common in children with autism spectrum disorder (ASD), we sought to define the relationship between MET-expressing (MET+) neurons in the DMV and $\mathrm{nAmb}$, and the gastrointestinal tract. Using wholemount tissue staining and clearing, or retrograde tracing in a $M E T^{E G F P}$ transgenic mouse, we identify three novel subpopulations of EGFP+ vagal brainstem neurons: ${ }^{1)}$ EGFP+ neurons in the nAmb projecting to the esophagus or laryngeal muscles, ${ }^{2)}$ EGFP+ neurons in the medial DMV projecting to the stomach, and ${ }^{3)}$ EGFP+ neurons in the lateral DMV projecting to the cecum and/or proximal colon. Expression of the MET ligand, hepatocyte growth factor (HGF), by tissues innervated by vagal motor neurons during fetal development reveal potential sites of HGF-MET interaction. Furthermore, similar cellular expression patterns of MET in the brainstem of both the mouse and nonhuman primate suggest that MET expression at these sites is evolutionarily conserved. Together, the data suggest that MET+ neurons in the brainstem vagal motor nuclei are anatomically positioned to regulate distinct portions of the gastrointestinal tract, with implications for the pathophysiology of gastrointestinal comorbidities of ASD.

Corresponding Author: Pat Levitt, PhD, Children's Hospital Los Angeles, Mail Stop \#135, 4650 Sunset Blvd, Los Angeles, CA 90027, plevitt@med.usc.edu, 323-361-7868. 


\section{Keywords}

gastrointestinal; neurodevelopment; dorsal motor nucleus of the vagus; nucleus ambiguus; gene expression; RRID:AB_300798; RRID:AB_10000240; RRID:AB_331361; RRID:AB_355414; RRID:SCR_00271

\section{INTRODUCTION}

Technical advances in gene profiling have led to an increase in efforts to characterize, at the molecular level, subpopulations of neurons (Molyneaux et al., 2009; 2014; Okaty et al., 2015; Wylie et al., 2010). This strategy has served as a platform to determine the relation between molecularly distinct neuronal subtypes, their connectivity phenotypes and eventually how neurons with shared molecular profiles are functionally unique. We recently identified a subset of vagal motor neurons that highly express the MET receptor tyrosine kinase (MET) during mouse brainstem development (Wu \& Levitt, 2013). MET is a highly pleiotropic receptor that is activated by hepatocyte growth factor (HGF), and mediates several developmental processes in the central nervous system and the periphery. While originally described for its role in liver cell proliferation, and as a motility factor for epithelial cells, HGF-MET signaling also regulates neocortical and enteric neuron dendrite growth, neocortical and hippocampal synapse formation and rate of maturation, development of non-sensory structures of the mammalian cochlea that impact hearing, and spinal and cranial motor neuron chemoattraction and survival (Avetisyan et al., 2015; Caton et al., 2000; Ebens et al., 1996; Gutierrez, Dolcet, Tolcos, \& Davies, 2004; Judson, Eagleson, Wang, \& Levitt, 2010; Lim \& Walikonis, 2008; Nakamura et al., 1989; Peng et al., 2016; Qiu, Lu, \& Levitt, 2014; Schmidt et al., 1995; Shibata, Miwa, Wu, Levitt, \& Ohyama, 2016; Stoker, Gherardi, Perryman, \& Gray, 1987; Xie, Eagleson, Wu, \& Levitt, 2016) for review see (Eagleson, Xie, \& Levitt, 2016b).

A promoter variant that regulates gene expression of $M E T$ (the rs $1858830 \mathrm{C}$ allele), as well as a truncating mutation in a family pedigree, have been associated with autism spectrum disorder (ASD) (Campbell et al., 2006; Lambert et al., 2014; Sousa et al., 2009; Thanseem et al., 2010). The rs $1858830 \mathrm{C}$ allele is also associated with ASD in children whose mothers express autoantibodies to fetal brain proteins (Heuer, Braunschweig, Ashwood, Van de Water, \& Campbell, 2011). This common variant is significantly enriched in children with both ASD and co-occurring gastrointestinal disturbances (GID) compared to ASD-only or unaffected children (Campbell et al., 2009). Overall, children with ASD are more than four times as likely to have a GID compared to non-ASD individuals, most commonly presenting with constipation and abdominal pain (Aldinger, Lane, Veenstra-VanderWeele, \& Levitt, 2015; Chaidez, Hansen, \& Hertz-Picciotto, 2013; Chandler et al., 2013; Gorrindo et al., 2012; Ibrahim, Voigt, Katusic, Weaver, \& Barbaresi, 2009; McElhanon, McCracken, Karpen, \& Sharp, 2014; Valicenti-McDermott et al., 2006). In addition, a high prevalence of food selectivity may either be an indication of GID in children with ASD, or contribute to GID in extreme cases (Emond, Emmett, Steer, \& Golding, 2010; Levy et al., 2007; RD et al., 2010). There is convergence of MET involvement in both ASD and GID. However, the biological significance of levels of MET expression and receptor signaling in relation to 
gastrointestinal function, particularly with a co-diagnosis of ASD, may be complex, given that the receptor is expressed in relevant brainstem nuclei, and in peripheral cell populations in the alimentary tract (Avetisyan et al., 2015; Sonnenberg, Meyer, Weidner, \& Birchmeier, 1993; Wu \& Levitt, 2013). Deep phenotyping, developmentally and in young adults, may provide opportunities to determine the role of MET in the central regulation of gastrointestinal function.

Vagal motor activity is known to modulate gastrointestinal function through innervation arising from the dorsal motor nucleus of the vagus (DMV) and nucleus ambiguus (nAmb) in the brainstem. Bilateral projections from the DMV and nAmb course peripherally along with sensory projections arising from the nodose ganglia to innervate the heart, airways, liver, kidney, pancreas, and gastrointestinal tract from the esophagus to the ascending colon (Berthoud, Carlson, \& Powley, 1991; Bieger \& Hopkins, 1987; Fox \& Powley, 1985). Specific subsets of vagal neurons, defined by their projections, coordinate distinct motor programs including modulation of gastrointestinal motility, opening of the lower esophageal sphincter, stimulation of gastric acid release, and pancreatic secretion (Dragstedt, Harper, Tovee, \& Woodward, 1947; Rattan \& Goyal, 1974; Schwartz, Holst, \& Fahrenkrug, 1978) for review see (Furness, Callaghan, Rivera, \& Cho, 2014). The vagal motor nuclei are highly organized forming a viscerotopic map delineated by connectivity to each target tissue (Berthoud et al., 1991; Bieger \& Hopkins, 1987; Fox \& Powley, 1985). Understanding of vagal motor neuron function in health and disease has been advanced by relating functional data from selective vagotomy and electrophysiology, with detailed anatomical tracing and mapping of the viscerotopic organization of the DMV and nAmb. Here, we report data probing cell-type specific phenotypes within the vagal motor nuclei that focus on neurons that express the MET receptor. Using a $M e t^{E G F P}$ transgenic reporter line, in situ hybridization, immunocytochemistry, and retrograde tracing, we determine the timing of MET expression in the developing brainstem in mouse and nonhuman primate, classify the neurochemical phenotypes of the MET expressing subpopulation, as well as identify target organs innervated. Furthermore, through analyzing $H g f$ gene expression in both the central nervous system and periphery, we identify putative sites of action of HGF-MET signaling as the vagus nerve establishes connectivity.

\section{METHODS}

\section{Animals}

Animal care and experimental procedures were performed in accordance with the Institutional Animal Care and Use Committee of the Saban Research Institute, Children's Hospital Los Angeles. Mice were housed at $22^{\circ} \mathrm{C}$ on a $13: 11 \mathrm{hr}$ light:dark cycle (lights on at 0600hrs:lights off at 1900hrs) with ad libitum access to a standard chow diet (PicoLab Rodent Diet 20, \#5053, St. Louis, MO).

A number of experiments utilized a newly derived $M e t^{E G F P}$ reporter mouse, using a BAC clone (BX139) from the GENSAT project at the Rockefeller University (RRID:SCR_002721, D. Geschwind, 2004). The clone was purchased from Children's Hospital Oakland Research Institute. BX139 contains an insertion of EGFP in the Met gene upstream of the ATG start codon on BAC clone RP23-173P9 (Gong, Kus, \& Heintz, 2010). 
Injection of BX139 into FVB fertilized eggs (Cyagen Biosciences Inc.) produced 5 founders, as determined by PCR for the presence of EGFP. EGFP+ F1 mice from each founder were crossed with C57BL/6J (RRID:IMSR_JAX:000664, The Jackson Laboratory), and maintained on a mixed background of FVB and C57BL/6J. Multiplex in situ hybridization was used in the brainstem raphe and neocortex to show that the expression of EGFP recapitulates endogenous Met transcript expression in founder lines (Kast, et al., 2017). Here, brains from mice of the F1 generation carrying the BX139 transgene (determined by PCR) were examined on postnatal day (P) 0 for EGFP and MET immunoreactivity (see below). Line 17 and line 18 exhibited the greatest fluorescence intensity for EGFP, and expression patterns of EGFP that coincided with the pattern of MET at this age. All analyses were carried out using subsequent generations of line 18, designated as $M e t^{E G F P}$. This line has a copy number of 6 EGFP transgene insertions based on a Taqman GFP Copy Number Assay (Thermo Fisher Scientific). Homozygous $M e t^{E G F P / E G F P}$ mice derived from $\mathrm{F} 1$ crosses were interbred to produce all $M e t^{E G F P / E G F P}$ mice used in the study. Detection of EGFP+ neurons and processes were thus considered as reporting the MET phenotype.

\section{Immunostaining}

Tissue for immunofluorescence staining was collected from mice on embryonic day (E) $11.5,13.5$, and 16.5, and P0, 7, 14, 25, 45, and 60. Tissue samples from both male and female mice were collected on P25 and P45, and assessed immunocytochemically for differential patterns of MET expression in the DMV and nAmb between sexes. Neuronal somata and processes that exhibit MET immunostaining are designated as MET+. There were no obvious differences between sexes in the intensity of MET immunofluorescence or the cellular pattern of MET ${ }^{\mathrm{EGFP}}$ expression at either P25 or P45. Thus, all postnatal data reported here are from male mice. For embryonic samples, sex was not determined, and the day of vaginal plug detection was designated as E0.5. Mice used on or prior to P0 were anesthetized by cold exposure followed by acute decapitation. Mice used on or after P7 were deeply anesthetized by intraperitoneal injection of ketamine: xylazine $(100 \mathrm{mg} / \mathrm{kg}: 10$ $\mathrm{mg} / \mathrm{kg}$, Henry Schein, Melville, NY) and perfused with $0.9 \%$ saline, followed by fixative (4\% paraformaldehyde (Sigma, St. Louis, MO) in 0.1M phosphate buffered saline (PBS), pH 7.4). Tissue collected was postfixed in $20 \%$ sucrose in fixative, cryoprotected overnight in $20 \%$ sucrose in PBS, embedded in VWR Clear Frozen Section Compound (VWR, Radnor, PA), and frozen on powdered dry ice. Four series of $20 \mu \mathrm{m}$ sections were cut using a cryostat, mounted onto superfrost plus microscope slides (VWR, Radnor, PA), and processed for immunostaining. Briefly, slides were incubated for $2 \mathrm{hr}$ in blocking buffer containing 5\% normal donkey serum (Jackson ImmunoResearch, West Grove, PA) and 0.3\% triton-X100 (Sigma, St. Louis, MO) in PBS, followed by incubation overnight in PBS containing 2\% normal donkey serum, $0.3 \%$ triton-X100, and primary antibodies directed against one or more of the following antigens: Cocaine- and amphetamine-regulated transcript (CART) (Phoenix Pharmaceuticals Cat\# H-003-62, RRID:AB_2313614), Choline Acetyltransferase (ChAT) (Millipore Cat\# AB144P, RRID:AB_2079751), Green Fluorescent Protein (GFP) (Abcam Cat\# ab13970, RRID:AB_300798), MET receptor tyrosine kinase (MET) (R and D Systems Cat\# AF527, RRID:AB_355414), Neurofilament (DSHB Cat\# 2H3, RRID:AB_531793), or Tyrosine Hydroxylase (TH) (Millipore Cat\# AB152, 
RRID:AB_390204). After several rinses in PBS, tissue was then incubated for $2 \mathrm{hr}$ at room temperature in PBS containing 2\% normal donkey serum, $0.3 \%$ triton-X100, and one or more of the following species-specific secondary antibodies: Alexa Fluor ${ }^{\circledR} 488$ AffiniPure $\mathrm{F}\left(\mathrm{ab}^{\prime}\right)_{2}$ Fragment Donkey Anti-Chicken IgG (Jackson ImmunoResearch Labs Cat\# 703-546-155, RRID:AB_2340376), Biotin-SP-AffiniPure F $\left(\mathrm{ab}^{\prime}\right)_{2}$ Fragment Donkey AntiGoat IgG (Jackson ImmunoResearch Labs Cat\# 705-066-147, RRID:AB_2340398), DyLight 549 Streptavidin (Vector Laboratories Cat\# SA-5549, RRID:AB_2336408), Alexa Fluor® 647 Donkey anti-Goat IgG (Thermo Fisher Scientific Cat\# A-21447, RRID:AB_2535864), Cy3-AffiniPure Donkey Anti-Rabbit IgG, (Jackson ImmunoResearch Labs Cat\# 711-165-152, RRID:AB_2307443), Alexa Fluor® 647 Donkey anti-Rabbit IgG, (Thermo Fisher Scientific Cat\# A-31573, RRID:AB_2536183), and/or Alexa Fluor® 647 Donkey anti-Mouse IgG (Thermo Fisher Scientific Cat\# A-31571, RRID:AB_2536181). After several rinses in PBS, sections were dried and a coverslip applied using fluoromount $\mathrm{G}$ mounting medium (Southern Biotech, Birmingham, AL).

\section{3,3'-Diaminobenzidine (DAB) Staining}

Brainstem sections from prenatal rhesus macaques were obtained from Dr. David Amaral (University of California, Davis ( $\mathrm{n}=1$ for two ages). Following standard laboratory procedures, animals were deeply anesthetized on gestational day (GD) 123 and 151 by intravenous injection of sodium pentobarbital $(50 \mathrm{mg} / \mathrm{kg}$, Fatal-Plus, Vortech Pharmaceuticals) and transcardial perfusion with $1 \%$ and $4 \%$ paraformaldehyde in PBS, pH 7.4 (P. Lavenex, Lavenex, Bennett, \& Amaral, 2009). Brains were postfixed in fixative for 6 $\mathrm{hr}$, cryoprotected in $10 \%$ and $20 \%$ glycerol in $0.1 \mathrm{M} \mathrm{PBS}$, and snap frozen in isopentane. A sliding microtome was used to collect 50 $\mathrm{mm}$-thick sections in cryoprotectant and stored at $-80^{\circ} \mathrm{C}$ until being shipped to Children's Hospital Los Angeles (CHLA). Here, sections were stored at $-80^{\circ} \mathrm{C}$ until used for MET and ChAT immunohistochemical processing, as previously described (Judson, Bergman, Campbell, Eagleson, \& Levitt, 2009). Briefly, sections were washed several times in PBS and incubated for 5 min in $0.3 \% \mathrm{H}_{2} \mathrm{O}_{2}$ (Sigma, St. Louis, MO) in methanol to eliminate endogenous peroxidase activity. Sections were then washed several times in PBS, 0.1M Tris-Glycine, washed again in PBS, and blocked in Blotto (4\% Carnation dried milk, 0.2\% Triton-X in PBS). Sections were incubated overnight at $4{ }^{\circ} \mathrm{C}$ in blocking solution containing primary antibodies directed against MET (Cell Signaling Technology Cat\# 3127, RRID:AB_331361) or ChAT (Millipore Cat\# AB144P, RRID:AB_2079751). Sections were then washed several times in Blotto, and incubated for 1 $\mathrm{hr}$ at room temperature in Blotto containing Biotin-SP-AffiniPure $\mathrm{F}\left(\mathrm{ab}^{\prime}\right)_{2}$ Fragment Donkey Anti-Mouse IgG (Jackson ImmunoResearch Labs Cat\# 715-066-150, RRID:AB_2340787) or Biotin-SP-AffiniPure $\mathrm{F}\left(\mathrm{ab}^{\prime}\right)_{2}$ Fragment Donkey Anti-Goat IgG (Jackson ImmunoResearch Labs Cat\# 705-066-147, RRID:AB_2340398). After washing in PBS, sections were incubated for $1 \mathrm{hr}$ in Vectastain ABC Elite solution (Vector Labs, Burlingame, CA, RRID:AB_2336819), washed in PBS, and incubated for 4 minutes in ImmPACT DAB Peroxidase (HRP) Substrate (Vector Labs, Burlingame, CA, RRID:AB_2336520). Sections were then washed in PBS, mounted onto superfrost plus slides, dehydrated in ascending concentrations of ethanol followed by D-Limonene (VWR, Radnor, PA), and a coverslip applied using DPX mounting medium. 
As a reference marker for neuronal subpopulations in the rhesus macaque brainstem, ChAT immunostaining was performed to localize cholinergic neurons in sections proximal to the GD151 brainstem sections used for MET immunostaining. In addition, for assisting with determining the anatomical location of MET expressing neurons, the reference series in GD120 rhesus macaque (NIH Blueprint NHP Atlas, RRID:SCR_010559) of acetylcholinesterase in situ hybridization, and a reference atlas of the adult rhesus macaque brain (Paxinos, 2009) were used.

\section{Wholemount Immunostaining and Tissue Clearing}

Wholemount analysis of antigen localization was performed in mouse embryos processed for tissue clearing using the iDISCO protocol (Renier et al., 2014). On E11.5 and E13.5, embryos were immersion fixed in $4 \%$ paraformaldehyde in $\mathrm{PBS}(\mathrm{pH} 7.4)$ overnight at $4{ }^{\circ} \mathrm{C}$, and dehydrated in 50\% methanol in PBS for $1 \mathrm{hr}, 80 \%$ methanol in PBS for $1 \mathrm{hr}$, and 100\% methanol twice for $1 \mathrm{hr}$. Samples were then bleached in chilled $5 \% \mathrm{H}_{2} \mathrm{O}_{2}$ in $20 \%$ DMSO/ methanol (1 volume $30 \% \mathrm{H}_{2} \mathrm{O}_{2}, 1$ volume DMSO, 4 volumes methanol) at $4^{\circ} \mathrm{C}$ overnight. Following bleaching, samples were washed 3 times in 100\% methanol for $1 \mathrm{hr}$, and 2 times in $20 \% \mathrm{DMSO} / \mathrm{methanol}$ for $1 \mathrm{hr}$. Samples were rehydrated in descending concentrations of methanol (80\% methanol in PBS, 50\% methanol PBS, 0\% methanol in PBS) for $1 \mathrm{hr}$ at each methanol concentration, and then incubated in PBS overnight. Samples were washed in PBS/0.2\% TritonX-100 2 times for $1 \mathrm{hr}$ each, and incubated in PBS/0.2\% TritonX-100/20\% $\mathrm{DMSO} / 0.3 \mathrm{M}$ glycine at $37^{\circ} \mathrm{C}$ overnight. Samples were blocked in PBS/0.2\% TritonX-100/10\% DMSO/6\% normal donkey serum at $37^{\circ} \mathrm{C}$ for 1 to 3 days, depending upon the age of the sample (Renier et al., 2014). Following 2 washes in PBS/0.2\% Tween-20 with $10 \mathrm{ug} / \mathrm{ml}$ heparin $(\mathrm{PTwH})$ for $1 \mathrm{hr}$ each, samples were incubated in primary antibodies directed against GFP (Aves Labs Cat\# GFP-1020, RRID:AB_10000240) and neurofilament (DSHB Cat\# 2H3, RRID:AB_531793) in PTwH/5\%DMSO/3\% Donkey Serum at 37 ${ }^{\circ} \mathrm{C}$ for 1 to 3 days. Several washes in PTwH for $10 \mathrm{~min}, 15 \mathrm{~min}, 30 \mathrm{~min}, 1 \mathrm{hr}, 2 \mathrm{hr}$, then overnight were used to eliminate unbound primary antibody. Embryos were then incubated in secondary antibody dilutions in PTwH/3\% normal donkey serum at $37^{\circ} \mathrm{C}$ for 1 to 3 days, washed in PTwH for $10 \mathrm{~min}, 15 \mathrm{~min}, 30 \mathrm{~min}, 1 \mathrm{hr}, 2 \mathrm{hr}$, then overnight to eliminate unbound secondary antibody.

Tissue was cleared by overnight incubation in $10 \mathrm{~mL}$ of $50 \% \mathrm{v} / \mathrm{v}$ Tetrahydrofuran $/ \mathrm{H}_{2} \mathrm{O}(\mathrm{THF}$, Sigma $186562-2 \times 100 \mathrm{ML}$ ) in a glass vial with a silicon-coated cap (Thermo Fisher Scientific C326-0020), followed by incubation for $1 \mathrm{hr}$ in $10 \mathrm{~mL}$ of $80 \% \mathrm{THF} / \mathrm{H}_{2} \mathrm{O}$, and incubation twice for $1 \mathrm{hr}$ in 100\% THF. Samples were incubated in dichloromethane (Sigma 270997-12×100ML) for approximately 5 to $10 \mathrm{~min}$, and dibenzyl ether (Sigma 108014-1KG) until tissue appeared to be fully clear.

\section{Antibody Characterization}

Antibodies used in this study are summarized in Table 1, and described in greater detail by corresponding number below.

1. The polyclonal rabbit anti-CART antibody (RRID:AB_2313614) recognizes mouse, rat, bovine, and human CART peptide 55-102, with some crossreactivity to human CART peptide 61-102, as indicated by the manufacturer. 
Specificity of this antibody has been demonstrated by preabsorption with 10ug/mL CART peptide 55-102, which is sufficient to abolish staining in rat pelvic ganglia (N. J. Dun, Dun, Wong, Yang, \& Chang, 2000). Patterns of immunoreactivity in histological staining with RRID:AB_2313614 are consistent with those using other CART antibodies (S. L. Dun, Castellino, Yang, Chang, \& Dun, 2001; Parker, Kumar, Lonergan, \& Goodchild, 2013), as well as our own staining for CART in the brainstem of developing and adult mice.

2. Antibodies directed against ChAT used in this study have been widely used in a variety of species including mouse (Corsi \& Coyle, 1991; Gautron et al., 2013), rat (Bhagwandin, Fuxe, \& Manger, 2006), cat (Shiromani et al., 1987), zebrafish (Clemente et al., 2004), monkey (H. T. Chang \& Kuo, 1991; Puller, Manookin, Neitz, Rieke, \& Neitz, 2015), and human (German, Bruce, \& Hersh, 1985). The original investigators generating this antibody demonstrate specificity, as only a single band around $68-70 \mathrm{kDa}$ was recognized following SDS-PAGE of the ammonium sulfate fraction of placental tissue sample (Bruce, Wainer, \& Hersh, 1985). In addition, immunohistochemical staining using ChAT antibody in our study is consistent with previously reported anatomical patterns of acetylcholinesterase expression in both mouse and monkey (Gautron et al., 2013; Jacobowitz \& Abbott, 1997; Paxinos, 2009).

3. Two chicken anti-GFP antibodies were used in this study, the first of which recognizes a single band around $25 \mathrm{kDa}$ in western blots from HEK293 cells transfected with GFP according to the manufacturer. Furthermore, no staining is observed in tissue from wild-type cell lysates.

4. The second chicken anti-GFP antibody used in this study was used specifically for iDISCO tissue processing, as it is compatible with methanol treatment (Renier et al., 2014). The manufacturer reports that samples from transgenic animals expressing GFP analyzed by western blot exhibit a single $25 \mathrm{kDa}$ band. Both GFP antibodies used in this study displayed identical patterns of immunoreactivity in brainstem sections from $\mathrm{MET}^{\mathrm{EGFP}}$ reporter mice.

5. Two separate anti-MET antibodies were used in this study to identify MET in samples from the mouse and non-human primate. Mouse monoclonal anti-MET antibody, RRID:AB_331361, was used to identify MET protein in rhesus macaque brainstem sections. Western blot data provided by the manufacturer demonstrates that this antibody recognizes both MET and pro-MET protein in cell lysates from several cell lines. This is consistent with western blot data from whole brain lysates from GD152 rhesus macaque (Judson, Amaral, \& Levitt, 2011). Staining of GD152 rhesus macaque cortical tissue sections with this antibody compared to other MET antibodies demonstrates consistent patterns of immunoreactive signal (Judson et al., 2011).

6. A second antibody, goat polyclonal anti-MET antibody, RRID:AB_355414, was used to localize MET protein in mouse brainstem. Specificity of this antibody has been demonstrated in western blots from wild-type mice recognizing a single band at approximately $145 \mathrm{kD}$, whereas no band is detected in cortical tissue 
samples from conditional null mice in which MET was deleted from the dorsal pallium (Eagleson, Milner, Xie, \& Levitt, 2013). Immunofluorescence staining with RRID:AB_355414 is consistent with in situ hybridization data (Wu \& Levitt, 2013), as well as patterns of immunoreactivity observed using the mouse monoclonal MET antibody described above.

7. Monoclonal anti-neurofilament antibodies used in this study were originally developed using E14-E15 rat spinal cord as the immunogen (Dodd, Morton, Karagogeos, Yamamoto, \& Jessell, 1988). The antibody recognizes a 155$165 \mathrm{kDa}$ band in western blots from PC12 cells and spinal cord tissue (Bampton \& Taylor, 2005) similar to the estimated weight of intermediate-sized cytoskeletal protein (Myers, Lazzarini, Lee, Schlaepfer, \& Nelson, 1987). Immunofluorescence staining in mouse tissue in the current study is consistent with the pattern of immunoreactivity described in previous studies (Cordes, 2001).

8. The polyclonal rabbit anti-TH antibody (RRID:AB_390204) recognizes human, rat, and mouse TH peptide according to the manufacturer. Extensive characterization of this antibody has been performed demonstrating that it recognizes a single band of approximately $62 \mathrm{kDa}$ in both mouse and zebrafish neural tissue samples (K. Yamamoto, Ruuskanen, Wullimann, \& Vernier, 2010). Furthermore, patterns of immunoreactivity for this antibody in brain tissue are similar across several mammalian species including rats, mice, hamsters, and prairie voles (Northcutt, Wang, \& Lonstein, 2006).

\section{In Situ Hybridization}

Fetal mice, on E13.5 and E15.5, were prepared for in situ hybridation (Eagleson et al., 2016a; Wu \& Levitt, 2013). The uterine horns were removed and fetuses were dissected in ice cold PBS, fixed in $4 \%$ paraformaldehyde in PBS (pH 7.4) overnight at $4{ }^{\circ} \mathrm{C}$, and cryoprotected in 30\% sucrose in PBS. Embryos were embedded in VWR Clear Frozen Section Compound, frozen in liquid nitrogen vapors, and stored at $-80^{\circ} \mathrm{C}$ until cut by cryostat into $20 \mu \mathrm{m}$ tissue sections. The following digoxigenin-labeled cRNA probes were used for in situ hybridization (ISH): mouse $\operatorname{Met}$ (2,665-4,051 bp of GenBank No. NM_008591) (Judson et al., 2009) and mouse Hgf (176-966 bp of GenBank No. AK042121). ISH was performed as described previously (Wu \& Levitt, 2013; Wu et al., 2009). Briefly, slides were fixed in $4 \%$ paraformaldehyde in PBS for $20 \mathrm{~min}$ at room temperature, washed several times in PBS, and treated with proteinase $\mathrm{K}(1-1.25 \mu \mathrm{g} / \mathrm{ml})$ for $15 \mathrm{~min}$. Tissue was acetylated for $10 \mathrm{~min}$ in triethanolamine (TEA-HCl, pH8.0) and prehybridized for 2 or more $\mathrm{hr}$ at $60^{\circ} \mathrm{C}$ in hybridization solution $(50 \%$ deionized formamide, $5 \times$ saline sodium citrate (SSC), pH 7.0, $1 \times$ Denhardt's solution, $0.1 \%$ Tween-20, $0.1 \%$ CHAPS, $5 \mathrm{mM}$ EDTA, pH 8.0, $100 \mu \mathrm{g} / \mathrm{ml}$ heparin, $300 \mu \mathrm{g} / \mathrm{ml}$ yeast tRNA in DepC- $\mathrm{H}_{2} \mathrm{O}$ ). Tissue was then incubated for 16 to $18 \mathrm{hr}$ at $60^{\circ} \mathrm{C}$ in hybridization solution containing probe. Following hybridization, slides were washed 3 times for $45 \mathrm{~min}$ each, at $65^{\circ} \mathrm{C}$ in washing solution ( $2 \times \mathrm{SSC}, \mathrm{pH} 4.0,50 \%$ formamide, $1 \%$ SDS in distilled water), then 3 times for 15 min in TBST ( $25 \mathrm{mM}$ Tris-HCL, pH 7.5, $136 \mathrm{mM} \mathrm{NaCl}, 2.68 \mathrm{mM} \mathrm{KCl}, 1 \%$ Tween-20 in distilled water) with gentle agitation at room temperature. Slides were then blocked for $1 \mathrm{hr}$ 
at room temperature with blocking reagent (100 mM Tris- $\mathrm{HCl}, \mathrm{pH} 7.5,150 \mathrm{mM} \mathrm{NaCl}, 1.5 \%$ Blocking Reagent (Roche, Indianapolis, Ind., USA)), and incubated at $4{ }^{\circ} \mathrm{C}$ overnight in solution with alkaline phosphatase-conjugated anti-DIG Fab fragments (1:2,000; Roche Cat\# 11093274910, RRID:AB_514497). The slides were then washed 3 times with TBST followed by NTMT solution (100 mM NaCl, $100 \mathrm{mM}$ Tris- $\mathrm{HCl}$, pH 9.5, $25 \mathrm{mM} \mathrm{MgCl} 2,1 \%$ Tween-20, $2 \mathrm{mM}$ levamisole) for $10 \mathrm{~min}$. Colorimetric reaction was developed with BM Purple (Roche Diagnostics Corporation, Indianapolis, IN).

Multiplex Fluorescent In Situ Hybridization-Fresh frozen brains from Met ${ }^{\mathrm{EGFP}}$ mice were cryosectioned at $16 \mu \mathrm{m}$ and processed according to a commercially available RNAscope Multiplex Fluorescent Assay Kit (Advanced Cell Diagnostics, Hayward, CA) as described previously (Kast, Wu, Williams, Gaspar, \& Levitt, 2017). RNAscope probes used in this study include: Met (cat\# 405301), Gfp (cat\# 400281), and Chat (cat\# 410071).

\section{Cholera Toxin, subunit B, Injections}

Male mice, aged P60 to P70, were anesthetized by isoflurane inhalation delivered with medical grade oxygen ( $4 \%$ isoflurane induction; $1-2 \%$ isoflurane maintenance). The mouse was placed in supine position on top of a heating pad and a $2.5 \mathrm{~cm}$ incision was made in the abdominal dermis, followed by a second, equally sized incision in the underlying abdominal muscle. Sterile ring forceps were used to gently exteriorize the gastrointestinal tract placing it on top of a sterile drape. A glass capillary needle (tip diameter approximately 20-50 $\mu \mathrm{m}$ ) attached to a microinjection system was back-filled by vacuum-assisted aspiration with a sterile solution of $1 \%$ fluorophore-conjugated cholera toxin B (CTB, Thermo Fisher, Waltham, MA) in phosphate buffer, as described by Conte, et al (Conte, Kamishina, \& Reep, 2009). Aided by the use of a surgical microscope, CTB solution was injected tangentially into the muscular wall of the gastrointestinal tract in 3 distinct sites: the stomach (antrum, body, and fundus were injected in each case), cecum, or the initial $2 \mathrm{~cm}$ of the colon. Several small 0.1-0.3 $\mu \mathrm{l}$ CTB injections were evenly placed along the length of each organ totaling 2-3 $\mu \mathrm{l}$ of CTB for each target injected. Following CTB injection, the abdominal cavity was rinsed with warm sterile saline to eliminate any potential contamination by CTB outside of the muscular tissue wall. The gastrointestinal tract was then repositioned inside the abdominal cavity and the abdominal muscles were sutured with absorbable 5-0 vicryl sutures. Ketoprofen $(5 \mathrm{mg} / \mathrm{kg})$ was administered subcutaneously to limit inflammation, and bupivacaine $(1 \mathrm{mg} / \mathrm{kg})$ was applied subcutaneously just prior to closure along the wound margin to provide analgesia. The overlying skin was closed with 5-0 PROLENE® suture, and the incision site was gently cleaned with chlorohexidine solution. After a 3-day survival period, mice were perfused transcardially with $4 \%$ paraformaldehyde buffered fixative and tissue was processed for immunohistochemistry, as described above.

\section{Imaging and Analysis}

Immunofluorescence images were acquired using a Zeiss LSM 710 laser scanning confocal microscope equipped with 10x, 20x, and 63× oil-corrected objectives. Confocal image stacks used for identification of vagal trajectories in wholemount iDISCO-processed tissue samples stained for EGFP and neurofilament were collected through the $z$-axis at a frequency of $7.36 \mu \mathrm{m}$ using a 10× objective. Imaris image analysis software (Bitplane, 
RRID:SCR_007370) was used to extract a contour map that served as a three-dimensional object rendering of the vagus nerve. This was accomplished by manually drawing an outline encompassing the contours of the nerve. The vagus was identified anatomically using localization of neurofilament immunoreactivity, and outlines were drawn on consecutive two-dimensional optical image slices throughout the entire image stack using the 'contour surface' tool. The extracted contour surface map containing the vagus nerve was used to generate a mask, such that all neurofilament staining except for the vagus was subtracted. In this ROI, which only contained the vagus nerve, colocalization of EGFP with neurofilament was assayed along the length of the nerve and its branches.

For cell counts of EGFP and CTB labeled neurons, every fourth consecutive section (20 $\mu \mathrm{m})$ was imaged through its entire thickness. Confocal image stacks were collected through the $z$-axis at a frequency of $1.14 \mu \mathrm{m}$ using a $20 \times$ objective. The 'cell counter' plugin in ImageJ software (version 1.46r, SCR_003070) facilitated manual counting of EGFP and CTB labeled neurons in confocal image stacks, for which the estimated number of cells per section was calculated in accordance with Abercrombie's formula (Abercrombie, 1946).

Images of sections processed for in situ hybridization were captured using a Zeiss Axio Observer inverted confocal microscope equipped with $2 \times$ and $5 \times$ objectives and a color CCD camera. Immunohistochemistry in rhesus macaque brainstem sections was visualized and imaged using a Leica DMI6000B inverted microscope equipped with a $10 \times$ objective and a color CCD camera.

All images are globally adjusted for brightness and contrast, and converted to TIFF format for publication using Adobe Photoshop CS5.

\section{Statistical Analysis}

Data are graphed using GraphPad Prism software (RRID:SCR_002798), and expressed as mean values \pm standard error of the mean. The nonparametric, Mann-Whitney test was used to compare the percentage of CTB labeled neurons colocalized with EGFP, rostral and caudal to the obex (Figure 8f).

\section{RESULTS}

\section{Ontogenesis of MET expression in developing vagal motor neurons}

Previous studies identified expression of MET in prenatal vagal motor neurons in the DMV and nAmb (Caton et al., 2000; Wu \& Levitt, 2013). However, no data are currently available detailing longer-term development and connectivity of this specific subpopulation of neurons. To address this, a developmental time course of MET expression prenatally in vagal motor neurons was established, followed by an analysis postnatally to determine whether MET continues to be expressed in the mature hindbrain. Consistent with previous reports, MET was expressed in the presumptive DMV and nAmb as early as E11.5 (Caton et al., 2000) (Figure 1a, g, and m). On E11.5, intense MET immunofluorescent profiles, consistent with developing neuropil labeling, and less intensely labeled neuronal somata were evident in the DMV and nAmb. Bright signal intensity of MET immunolabeling in the vagal motor nuclei was apparent throughout fetal development, but declined considerably after birth. At 
all postnatal ages examined, MET immunofluorescent signal was detectable within vagal motor nuclei. However, staining generally was limited to punctate neuropil labeling, a pattern that is typical for plasma membrane receptor proteins. Thus, the cytoplasmic staining of somata seen prenatally was absent at all postnatal ages examined.

In addition to examining the timing and pattern of MET expression based on immunolocalization of the receptor protein, the $M e t^{E G F P}$ transgenic reporter line was used to map EGFP+ neurons in the developing hindbrain. The pattern of EGFP expression in $M e t^{E G F P}$ mice corresponded closely with that identified by immunofluorescence staining for MET protein, demonstrating that the transgenic reporter mouse faithfully reproduces cellular patterns of MET expression (Figure 1). Furthermore, fluorescent in situ hybridization confirmed that mRNA for Met and Gfp are co-expressed by brainstem vagal motor neurons in $M e t^{E G F P}$ mice (Figure 2). A similar fidelity of co-expression is evident in a limited subset of dorsal raphe serotonergic neurons (Kast et al., 2017). Consistent with the timing of MET protein expression, EGFP immunoreactive signal in the DMV and nAmb was evident in neuronal somata early in embryonic development. In contrast to immunodetection patterns of the MET receptor observed in the neuropil of the adult vagal nuclei, cytoplasmic EGFP continued to be detected at P60 in the somata of a subset of vagal motor neurons. We did not identify any MET+ or EGFP+ nodose neuronal sensory afferent staining pre- or postnatally.

\section{MET is expressed by subsets of vagal motor neurons in the mouse and non-human primate}

The vagal motor nuclei are topographically organized according to visceral projection target. To relate this viscerotopic organization to the cellular distribution of MET-expressing populations, the positions of EGFP+ neurons were mapped within the DMV and nAmb along the rostral-caudal and medial-lateral axes. Within the DMV, EGFP+ neurons were found along the entire rostral to caudal extent of the nucleus. In the most anterior portions of the DMV, located rostral to the opening of the $4^{\text {th }}$ ventricle, EGFP+ neurons were scattered throughout the mediolateral extent of the nucleus (Figure $3 a$ and $b$ ). In contrast, at intermediate levels of the DMV, located caudal to the closure of the central canal, EGFP+ neurons were densely clustered only at the most lateral extent of the nucleus (Figure $3 \mathrm{c}$ and d). This lateral pattern of cellular EGFP expression extended caudally to the end of the DMV, where the nucleus narrows considerably, and medial-lateral patterning is more difficult to resolve (Figure 3e and f). Based on cellular distribution patterns of EGFP+ neurons, two anatomically, and likely functionally, distinct subsets of MET neurons may exist within the DMV.

Overall, the majority of neurons within the nAmb were EGFP+, but the extent of labeling varied among subregions (Figure $3 \mathrm{~g}$ and $\mathrm{h}$ ). In the more rostrally located compact formation, nearly all of the neurons were EGFP+. In contrast, within the semicompact formation, very few EGFP+ neurons were observed on P0. The extent of EGFP+ labeling in the semicompact formation increased during postnatal development and remained evident at P60. There also were EGFP+ neurons in the loose and external formations of the nucleus ambiguus, which supply the laryngeal nerves, and heart, respectively. 
In addition to the vagal motor nuclei, EGFP+ neurons were located in the caudal portion of the dorsal raphe nucleus, as reported by Kast et al (Kast et al., 2017), the spinal trigeminal nucleus, and neurons situated in the nucleus of the solitary tract. There also were a few, scattered EGFP+ neurons located at the lateral borders of the hypoglossal nucleus of the $12^{\text {th }}$ cranial nerve (n12), that were most apparent at perinatal ages (Figure 3c).

To determine whether these general brainstem patterns of MET expression are conserved in the developing primate, we processed for MET immunocytochemistry a series of fixed brainstem sections from third trimester rhesus monkeys at two different prenatal ages. There were similar patterns of MET protein expression to those observed in the mouse. On GD123 and GD151, MET was observed in a subpopulation of cells along the ventrolateral border of the DMV (Figure $4 \mathrm{~g}$ and $\mathrm{h}$ ). There was clear MET labeling of neuronal somata in the $\mathrm{nAmb}$ on GD123, but by GD151, immunostaining was reduced in intensity with more apparent neuropil labeling (Figure $4 \mathrm{a}$ and $\mathrm{b}$ ). In addition to the DMV and nAmb, MET immunostained neurons and neuropil were evident in the nucleus of the solitary tract, the spinal trigeminal nucleus, and the caudal portion of the dorsal raphe (Figure $4 \mathrm{~d}$ and e), consistent with patterns of MET expression described in the mouse (Kast et al., 2017; Wu \& Levitt, 2013).

\section{Neurotransmitter and neuropeptide phenotypes of vagal MET neurons}

To determine the neurotransmitter and neuropeptide phenotype of MET neurons in the DMV and nAmb on P0 and P60, we used antibodies against Choline Acetyltransferase (ChAT), cocaine- and amphetamine-regulated transcript (CART), and tyrosine hydroxylase (TH), all of which are expressed by discrete populations of brainstem vagal neurons. All EGFP+ neurons in the DMV and nAmb co-expressed ChAT, however, not all ChAT expressing neurons were EGFP+ (Figure 5a, b, g, and h). Of EGFP+ neurons in the lateral column of the DMV, 26.5\% $( \pm 4.8, \mathrm{n}=6)$ were also found to co-express CART at either P0 or P60 (Figure $5 \mathrm{c}$ and d). CART-immunoreactive puncta were evident in the neuropil of $\mathrm{nAmb}$, but none of these profiles were EGFP+ (Figure $4 \mathrm{i}$ and $\mathrm{j}$ ). TH was not co-expressed by EGFP+ neurons in either the DMV or nAmb at either age (Figure 5e, f, k, and l).

\section{Hgf is expressed by a subset of vagal brainstem targets}

The MET receptor tyrosine kinase is activated by binding its only known ligand, hepatocyte growth factor (HGF). HGF, however, is not expressed concurrently in the fetal brainstem (Wu \& Levitt, 2013). To determine whether peripheral tissues innervated by vagal motor neurons express HGF, and more broadly, to examine the relationship between Met and $\mathrm{Hgf}$ expression as vagal connections are established, in situ hybridization for Met and $H g f$ mRNA was performed on whole body sagittal sections at E13.5 and E15.5. At E13.5, Met transcript was observed in cells on the dorsal surface of the tongue, and in the ventral spinal cord (Figure 6a and a1). Modest expression was also detectable in the intestines (Figure 6b). At E15.5, Met expression in the developing intestines was much more apparent, appearing to line the inner epithelial surface (Figure $6 \mathrm{~d}$ and $\mathrm{d} 1$ ). At this time, Met also was observed in the spinal cord, kidney, lung, and trachea (Figure 6c, c1, and d). Expression patterns of $\mathrm{Hgf}$ were distinct from those of Met. On E13.5, $H g f$ was observed in cells on the ventral aspects of the tongue, and along the developing airways, esophagus, and heart (Figure 6e, e1, f, and 
f1). On E15.5, continued $H g f$ expression was observed in the esophagus, and also was evident in cells scattered in domains along the length of the gastrointestinal tract (Figure 6g, $\mathrm{g} 1, \mathrm{~h}$, and h1).

\section{MET expressing neurons exhibit complex peripheral projections}

To more fully understand the potential relationship between MET expression patterns and putative functional subgroups of vagal motor neurons, multiple methods were used. Experiments were designed using the $M e t^{E G F P}$ mouse line to determine the trajectories and innervation targets of vagal motor neurons that express EGFP. First, wholemount iDISCO immunostaining and tissue clearing was carried out in E11.5 and E13.5 embryos (Figure 7af). This allowed direct visualization of EGFP+ cell bodies in the brainstem, as well as providing an ability to map their axonal projections to specific peripheral targets. This strategy provides the ability to disambiguate vagal brainstem patterns of innervation from those that potentially could arise from sympathetic postganglionic neurons or enteric neurons, which express MET (Avetisyan et al., 2015; Maina et al., 1998).

Neurofilament staining was used as a marker to facilitate analysis of EGFP+ signal within peripheral axons. The subset of neurofilament labeling that corresponds to the vagus nerve was identified, along which the presence of EGFP+ labeling was assessed, using Imaris software (Figure $7 \mathrm{~b}$ and $\mathrm{c}$ ). Within the vagus nerve, EGFP+ axonal projections coursed along the length of the main vagal trunks (Figure 7e). A well-defined branch of the main trunk of the vagus contained EGFP+ axons that ascended rostrally, corresponding anatomically to the laryngeal nerves (Figure 7d), which supply innervation to the airways and pharyngeal constrictors. EGFP+ axons also were observed entering the gastric vagal branches along the stomach (Figure 7f).

The iDISCO methodology facilitated visualization of EGFP+ vagal trajectories. To further examine minor vagal branches and individual axonal fibers, whole body sagittal sections were cut and examined on E13.5, E16.5, and P0 for MET EGFP labeling, again using neurofilament staining to identify axonal projections. Consistent with results from iDISCO staining and tissue clearing, EGFP+ axons were evident in the laryngeal branches of the vagus, as well as in finer branches extending to the muscles surrounding the larynx (Figure $7 \mathrm{~g}$ ). Fine EGFP+ axons also were observed along the length of the external muscular layer of the esophagus (Figure 6h). In addition, a dense front of accumulated EGFP+ axons was observed enveloping the stomach (Figure 7i).

Lastly, to identify connections of EGFP+ vagal motor neurons to subdiaphragmatic targets in the gastrointestinal tract in the $M e t^{E G F P}$ transgenic mice, injections of the retrograde tracer, cholera toxin, subunit $\mathrm{B},(\mathrm{CTB})$ were made in adult mice. CTB injections were placed tangentially into the muscular walls of the antrum, body, and fundus of the stomach, cecum, or proximal two centimeters of the colon. Three days following surgery, the brainstems of injected animals were harvested and prepared for colocalization of EGFP and CTB labeling to determine the extent to which EGFP+ neurons project to each CTB injected site. Following CTB injection into the stomach, CTB-labeled neurons were observed throughout the entire rostral-caudal extent of the DMV, with the greatest number of CTB labeled neurons localized rostral to the opening of the $4^{\text {th }}$ ventricle (Figure $8 \mathrm{a}, \mathrm{b}$, and c). Cell counts 
revealed that $19.8 \%$ of stomach-projecting CTB-labeled neurons in the DMV colocalized with EGFP (Figure 8e). Using the obex, defined as the caudalmost portion of the area postrema, as a boundary, there was a unique distribution pattern of EGFP+ neurons labeled by CTB injection into the stomach. Only $5.1 \%$ of EGFP+ neurons caudal to the obex colocalized CTB, whereas colocalization significantly increased to $24.7 \%$ for EGFP +neurons situated rostral to the obex (Figure 8f), suggesting functional differences between the subgroups.

Patterns of CTB labeling in the DMV following injection into the cecum or proximal colon were very similar. In both instances, CTB-labeled neurons were located on the lateral edges of the DMV, and localized almost entirely to sections caudal to the opening of the $4^{\text {th }}$ ventricle (Figure $8 \mathrm{a}$ and $\mathrm{b}$ ). A remarkable $72.6 \%$ of CTB-positive (CTB+) cecum-projecting neurons, and $81.0 \%$ of CTB+ proximal colon-projecting neurons colocalized with EGFP (Figure 8e). CTB labeling was never observed in the nAmb following injections into the stomach, cecum, or proximal colon.

\section{DISCUSSION}

Gastrointestinal disturbances (GIDs) are common in children with ASD, potentially reflecting a shared biological vulnerability that could impact both neurological and gastrointestinal functions. In fact, there is shared genetic burden for psychiatric and cooccurring medical conditions that indicates convergent biological risk may be common between brain and periphery (Plummer, Gordon, \& Levitt, 2016). Consistent with this hypothesis, we reported previously an enrichment of a promoter variant in the MET gene in families of children with ASD and co-occurring GID, compared to children diagnosed with ASD only (Campbell et al., 2009). The promoter variant reduces MET expression by 30 50\%, measured in human immune cells (Heuer et al., 2011) and neocortex (Campbell et al., 2007; Voineagu et al., 2011). The underlying biological processes connecting ASD and GID are unknown, but could include central and peripheral involvement of shared risk factors, such as pleiotropic genes like $M E T$, or factors related to the gut microbiome (Sharon, Sampson, Geschwind, \& Mazmanian, 2016).

In the current study, we took advantage of a $M e t^{E G F P}$ transgenic mouse line, which we show here in the vagal brainstem, and in other studies (Kast et al., 2017), exhibits high fidelity expression of an EGFP reporter to label MET expressing neurons. In the following discussion, we refer to EGFP+ neurons in the $M e t^{E G F P}$ reporter line as MET+ neurons. Through detailed analysis of the development, anatomical position, and connectivity of MET + neurons in the DMV and nAmb, the data reveal a striking phenotypic specialization of vagal subpopulations in the brainstem that are positioned to affect GI function. The results also are consistent with each MET+ subpopulation positioned to modulate distinct portions of the alimentary tract, including the esophagus, stomach, cecum, and proximal colon. Furthermore, our results demonstrate that MET is expressed shortly after vagal motor neurons are generated, with a potential developmental role as these circuits develop. 


\section{MET+ subpopulations in the nAmb and DMV delineated by viscerotopic organization and connectivity}

Distinct subpopulations of MET+ vagal motor neurons were identified based on neuroanatomical position within the DMV or nAmb and their efferent connectivity to the gastrointestinal tract. These subpopulations consist of 1) MET+ neurons in the nAmb projecting to the esophagus or laryngeal muscles, 2) MET+ neurons in the medial DMV projecting to the stomach, and 3) MET+ neurons in the lateral DMV projecting to the cecum and/or proximal colon. The subgroups likely develop early, because the rostral-caudal and medial-lateral position of each MET+ subpopulation was evident as early as P0.

A large body of work has described the viscerotopic organization of the vagal motor nuclei, providing context for understanding the putative function of MET+ vagal neurons. Within the nAmb, four main subcompartments exist: the compact, semicompact, loose, and external formations (Altschuler, Bao, \& Miselis, 1991; Bieger \& Hopkins, 1987). The compact, semicompact, and loose formation are comprised of special visceral efferent neurons, while the ventrally located external formation is comprised of general visceral efferent neurons (Bieger \& Hopkins, 1987). The majority of MET+ neurons of the nAmb were positioned within the compact formation, a region containing neurons that project directly to motor endplates located in the striated muscle of the esophagus, as well as supplying the superior laryngeal branch of the vagus nerve (Bieger \& Hopkins, 1987; Neuhuber, Kressel, Stark, \& Berthoud, 1998; Pascual-Font et al., 2011). iDISCO analysis and immunostaining in sections further confirmed innervation of the esophagus by EGFP+ axons. These vagal connections facilitate peristalsis and propulsion of ingested food down the length of the esophagus (Crist, Gidda, \& Goyal, 1984; A. K. M. M. D \& D, 1975; Kravitz, Snape, \& Cohen, 1978; Powley et al., 2013).

In addition to innervation of the esophagus, MET+ neurons project to the muscles surrounding the larynx. Special visceral efferent innervation of the laryngeal muscles arises from both the superior and recurrent laryngeal branches of the vagus (Bieger \& Hopkins, 1987; Pascual-Font et al., 2011). Neurons projecting within the superior laryngeal branch are located within the compact formation of the nAmb (Bieger \& Hopkins, 1987). By contrast, neurons projecting within the recurrent laryngeal branch are located within the loose formation of the nAmb (Bieger \& Hopkins, 1987). Localization of MET+ neurons in several nAmb subcompartments likely indicates innervation of separate targets, comprising multiple subpopulations of MET+ neurons. The present data provide a foundation for additional retrograde tracing experiments to resolve the degree of overlap of the projection patterns of these subpopulations.

Within the DMV, parasympathetic vagal motor neurons are viscerotopically organized into distinct columns aligned along the medial-lateral axis. Neurons located medially project within the paired (left and right) gastric branches of the vagus, while neurons located in the lateral aspects of the DMV project within the paired celiac branches of the vagus (Fox \& Powley, 1985). Using both the neuroanatomical position of MET+ neurons, and cellular labeling following retrograde tracing, the experiments identified two distinct subpopulations of MET+ neurons within the DMV. First, MET+ neurons in the medial DMV project to the stomach, where vagal efferents are suggested to make extensive contacts with approximately 
$66 \%$ of enteric neurons of the myenteric plexus (Schemann \& Grundy, 1992). This population of MET+ neurons in the medial DMV was largely localized rostral to the obex. Functional differences between gastric-projecting neurons located rostrally versus caudally within the DMV have been described in rodents using the excitatory neurotransmitter, glutamate (L-glu), to stimulate anatomically distinct subsets of DMV neurons.

Microinjection of L-glu in the rostral portions of the DMV facilitates increases in intragastric pressure and gastric contraction, while L-glu microinjection to the caudal DMV reduces intragastric pressure and mediates gastric relaxation (Krowicki et al., 2002; Monroe, Hornby, \& Partosoedarso, 2004; Zhou, Lu, Yao, \& Owyang, 2008). In addition, the rostral DMV receives dense thyrotropin-releasing hormone innervation from the caudal raphe nuclei that stimulates descending gastric contraction and gastric acid secretion (Hornby et al., 1989; H. Yang, Ohning, \& Taché, 1993). Therefore, the position of the rostrally located MET+ neurons that project to the stomach is consistent with a role in modulating gastric contraction, gastric emptying, or gastric acid secretion.

The lateral column of the DMV contains a distinct subpopulation of MET+ neurons, which project to either the cecum or proximal colon. Interestingly, in a pilot study, double injections using CTB conjugated to spectrally distinct fluorophores, consistently revealed a small overlap of approximately $15 \%$ of neurons projecting to both the cecum and proximal colon. This suggests that the MET+ neurons projecting to the cecum or proximal colon are mostly distinct subgroups, but do contain a proportion that overlap and may perform dual roles. Functionally, vagal neurons projecting to the cecum stimulate cecal contraction (Berthoud et al., 1991; Z. L. Lee \& Nakayama, 1981). Vagal stimulation also increases ileocecal sphincter pressure, which provides a barrier against reflux of bacteria-rich colonic contents into the small intestine (Phillips, Quigley, Kumar, \& Kamath, 1988; Rubin, Cardwell, Ouyang, Snape, \& Cohen, 1981). In addition, vagal neurons projecting to the proximal colon are thought to modulate increased contraction and motility in both rodents and primates (Dapoigny, Cowles, Zhu, \& Condon, 1992; Tong, Ridolfi, Kosinski, Ludwig, \& Takahashi, 2010). Thus, the laterally positioned population of MET+ neurons, together with medially located MET+ neurons in the DMV, and MET+ neurons of the nAmb, are each positioned to modulate control of distinct regions of the gastrointestinal tract. Future studies will be required to determine precisely how each population of MET+ neurons impacts gastrointestinal function.

\section{Implications of developmental expression of ligand and receptor}

HGF is absent from the embryonic brainstem as MET+ vagal neurons migrate and extend axonal projections to the viscera (Wu \& Levitt, 2013). Thus, it is likely that the expression patterns of HGF peripherally during development reflect putative sites of MET receptor activation on developing vagal axons from MET+ subpopulations of neurons. Outside of the nervous system, HGF was described originally for its role in liver cell proliferation and in epithelial cell motility (Nakamura et al., 1989; Stoker et al., 1987). HGF also acts as an epithelial cell morphogen in the kidney, lung, colon, and mammary glands (Brinkmann, Foroutan, Sachs, Weidner, \& Birchmeier, 1995; Y. Yang, Spitzer, Meyer, \& Sachs, 1995), as well as in tumor formation and metastasis (C. Birchmeier, Birchmeier, Gherardi, \& Vande Woude, 2003; Park et al., 1986; Rong et al., 1992). HGF also is critical for muscle formation 
in the developing tongue and limb buds (Bladt, Riethmacher, Isenmann, Aguzzi, \& Birchmeier, 1995; Scaal et al., 1999). Therefore, it is important to emphasize that not all sites of peripheral HGF expression are relevant to vagal brainstem MET+ neuron signaling, the focus of the current study. HGF is expressed in several developing sites to which MET+ vagal motor neurons project, as vagal efferents begin to contact the gastrointestinal tract (Rinaman \& Levitt, 1993). In situ hybridization experiments demonstrate that HGF is expressed in cells located in the airways, esophagus, and at scattered points along the intestines. Each of these sites is a target of MET+ vagal motor neurons, identified by either retrograde neuronal tracing experiments in adults, or analysis of wholemount iDISCO immunostaining embryonically. One potential inconsistency was the lack of HGF expression in the stomach of E13.5 or E15.5 mouse embryos. Studies in rat demonstrated a peak in HGF expression in fetal rat stomach around E19 (Matsubara, 1998). In addition, the mature enteric nervous system co-expresses both MET and HGF in a subset of neurons (Avetisyan et al., 2015). Therefore, the fetal ages that we examined in mice may have been too early to observe HGF expression in the stomach or enteric nervous system.

The mechanisms governing the growth and guidance of vagal motor efferents to the gastrointestinal tract, as well as the significance of HGF for these developmental processes are under investigation. HGF produced by the branchial arches serves as a potent chemoattractive and survival factor for cranial branchiomotor neurons (Caton et al., 2000). This could also apply to developing MET+ vagal motor neurons. However, studies performed in $h g f$ null embryos demonstrate that while the hypoglossal nerve exhibits severe defects, the vagus nerve appears relatively intact at a gross level (Caton et al., 2000). The vagus is a mixed nerve, however, composed of approximately $80 \%$ sensory axon fibers (Foley \& DuBois, 1937). Therefore, alterations in a small subset of vagal axons that are MET+, would likely go undetected without specific application of genetic tools for molecular labeling. These studies are underway in our laboratory.

\section{Biological points of convergence for ASD and GID}

As a point of convergence with co-morbidity for ASD and GID risk, we find here that the organization of developing and mature MET+ vagal motor neurons is consistent with a role in modulating function of the gastrointestinal tract through connections to the esophagus, stomach, cecum, and colon. Furthermore, the finding that MET also is expressed in the developing vagal complex of the primate brain suggests an evolutionarily conserved role for the receptor in this specific subset of MET+ neurons. Based on the anatomical results reported here, the putative function of these MET+ subpopulations may be to contribute to the modulation of motility along the gastrointestinal tract, regulate gastric acid secretion, or mediate closure of the ileocecal sphincter preventing reflux of colonic contents. The central regulation also could modulate the impact of disrupted MET signaling in cells that normally express the receptor, particularly enteric neurons and intestinal epithelia known to be important for motility and repair after injury (Avetisyan et al., 2015). Delineation of the role of the MET receptor in distinct normal and pathogenic neurodevelopmental and gastrointestinal functional processes will be possible with new tools for genetic dissection. 


\section{Acknowledgments}

The studies were supported by NIH R21NS086413, the Simms/Mann Chair in Developmental Neurogenetics and Team Science Grant at CHLA (PL). AK was supported by The Saban Research Institute Post-Doctoral Research Career Development Fellowship.

\section{References}

Abercrombie M. Estimation of nuclear population from microtome sections. The Anatomical Record. 1946; 94:239-247. [PubMed: 21015608]

Aldinger KA, Lane CJ, Veenstra-VanderWeele J, Levitt P. Patterns of Risk for Multiple Co-Occurring Medical Conditions Replicate Across Distinct Cohorts of Children with Autism Spectrum Disorder. Autism Research. 2015; 8(6):771-781. http://doi.org/10.1002/aur.1492. [PubMed: 26011086]

Altschuler SM, Bao XM, Miselis RR. Dendritic architecture of nucleus ambiguus motoneurons projecting to the upper alimentary tract in the rat. The Journal of Comparative Neurology. 1991; 309(3):402-414. http://doi.org/10.1002/cne.903090309. [PubMed: 1717520]

Avetisyan M, Wang H, Schill EM, Bery S, Grider JR, Hassell JA, et al. Hepatocyte Growth Factor and MET Support Mouse Enteric Nervous System Development, the Peristaltic Response, and Intestinal Epithelial Proliferation in Response to Injury. Journal of Neuroscience. 2015; 35(33):11543-11558. http://doi.org/10.1523/JNEUROSCI.5267-14.2015. [PubMed: 26290232]

Bampton ETW, Taylor JSH. Effects of Schwann cell secreted factors on PC12 cell neuritogenesis and survival. Journal of Neurobiology. 2005; 63(1):29-48. http://doi.org/10.1002/neu.20119. [PubMed: 15702477]

Berthoud HR, Carlson NR, Powley TL. Topography of efferent vagal innervation of the rat gastrointestinal tract. The American Journal of Physiology. 1991; 260(1 Pt 2):R200-7. [PubMed: 1992820]

Bhagwandin A, Fuxe K, Manger PR. Choline acetyltransferase immunoreactive cortical interneurons do not occur in all rodents: A study of the phylogenetic occurrence of this neural characteristic. Journal of Chemical Neuroanatomy. 2006; 32(2-4):208-216. http://doi.org/10.1016/j.jchemneu. 2006.09.004. [PubMed: 17049807]

Bieger D, Hopkins DA. Viscerotopic representation of the upper alimentary tract in the medulla oblongata in the rat: the nucleus ambiguus. The Journal of Comparative Neurology. 1987; 262(4): 546-562. http://doi.org/10.1002/cne.902620408. [PubMed: 3667964]

Birchmeier C, Birchmeier W, Gherardi E, Vande Woude GF. Met, metastasis, motility and more. Nature Reviews Molecular Cell Biology. 2003; 4(12):915-925. http://doi.org/10.1038/nrm1261. [PubMed: 14685170]

Bladt F, Riethmacher D, Isenmann S, Aguzzi A, Birchmeier C. Essential role for the c-met receptor in the migration of myogenic precursor cells into the limb bud. Nature. 1995; 376(6543):768-771. http://doi.org/10.1038/376768a0. [PubMed: 7651534]

Brinkmann V, Foroutan H, Sachs M, Weidner KM, Birchmeier W. Hepatocyte growth factor/scatter factor induces a variety of tissue-specific morphogenic programs in epithelial cells. The Journal of Cell Biology. 1995; 131(6 Pt 1):1573-1586. [PubMed: 8522613]

Bruce G, Wainer BH, Hersh LB. Immunoaffinity purification of human choline acetyltransferase: comparison of the brain and placental enzymes. Journal of Neurochemistry. 1985; 45(2):611-620. [PubMed: 4009177]

Campbell DB, Buie TM, Winter H, Bauman M, Sutcliffe JS, Perrin JM, Levitt P. Distinct Genetic Risk Based on Association of MET in Families With Co-occurring Autism and Gastrointestinal Conditions. Pediatrics. 2009; 123(3):1018-1024. http://doi.org/10.1542/peds.2008-0819. [PubMed: 19255034]

Campbell DB, D’Oronzio R, Garbett K, Ebert PJ, Mirnics K, Levitt P, Persico AM. Disruption of cerebral cortex MET signaling in autism spectrum disorder. Annals of Neurology. 2007; 62(3): 243-250. http://doi.org/10.1002/ana.21180. [PubMed: 17696172]

Campbell DB, Sutcliffe JS, Ebert PJ, Militerni R, Bravaccio C, Trillo S, et al. A genetic variant that disrupts MET transcription is associated with autism. Proceedings of the National Academy of 
Sciences of the United States of America. 2006; 103(45):16834-16839. http://doi.org/10.1073/ pnas.0605296103. [PubMed: 17053076]

Caton A, Hacker A, Naeem A, Livet J, Maina F, Bladt F, et al. The branchial arches and HGF are growth-promoting and chemoattractant for cranial motor axons. Development. 2000; 127(8):17511766. [PubMed: 10725250]

Chaidez V, Hansen RL, Hertz-Picciotto I. Gastrointestinal Problems in Children with Autism, Developmental Delays or Typical Development. Journal of Autism and Developmental Disorders. 2013; 44(5):1117-1127. http://doi.org/10.1007/s10803-013-1973-x.

Chandler S, Carcani-Rathwell I, Charman T, Pickles A, Loucas T, Meldrum D, et al. Parent-reported gastro-intestinal symptoms in children with autism spectrum disorders. Journal of Autism and Developmental Disorders. 2013; 43(12):2737-2747. http://doi.org/10.1007/s10803-013-1768-0. [PubMed: 23371507]

Chang HT, Kuo H. Relationship of calbindin D-28k and cholinergic neurons in the nucleus basalis of Meynert of the monkey and the rat. Brain Research. 1991; 549(1):141-145. [PubMed: 1893247]

Clemente D, Porteros Á, Weruaga E, Alonso JR, Arenzana FJ, Aijón J, Arévalo R. Cholinergic elements in the zebrafish central nervous system: Histochemical and immunohistochemical analysis. The Journal of Comparative Neurology. 2004; 474(1):75-107. http://doi.org/10.1002/cne. 20111. [PubMed: 15156580]

Conte WL, Kamishina H, Reep RL. Multiple neuroanatomical tract-tracing using fluorescent Alexa Fluor conjugates of cholera toxin subunit B in rats. Nature Protocols. 2009; 4(8):1157-1166. http://doi.org/10.1038/nprot.2009.93. [PubMed: 19617887]

Cordes SP. Molecular genetics of cranial nerve development in mouse. Nature Reviews Neuroscience. 2001; 2(9):611-623. http://doi.org/10.1038/35090039. [PubMed: 11533729]

Corsi P, Coyle JT. Nerve growth factor corrects developmental impairments of basal forebrain cholinergic neurons in the trisomy 16 mouse. Proceedings of the National Academy of Sciences of the United States of America. 1991; 88(5):1793-1797. [PubMed: 2000385]

Crist J, Gidda JS, Goyal RK. Intramural mechanism of esophageal peristalsis: roles of cholinergic and noncholinergic nerves. Proceedings of the National Academy of Sciences of the United States of America. 1984; 81(11):3595-3599. [PubMed: 6587375]

DAKMM, DNWWP. Neural Organization of Esophageal Peristalsis: Role of Vagus Nerve. Ygast. 1975; 68(3):444-447. http://doi.org/10.1016/S0016-5085(75)80080-1.

Dapoigny M, Cowles VE, Zhu YR, Condon RE. Vagal influence on colonic motor activity in conscious nonhuman primates. The American Journal of Physiology. 1992; 262(2 Pt 1):G231-6. [PubMed: 1539658]

Dodd J, Morton SB, Karagogeos D, Yamamoto M, Jessell TM. Spatial regulation of axonal glycoprotein expression on subsets of embryonic spinal neurons. Neuron. 1988; 1(2):105-116. [PubMed: 3272160]

Dragstedt LR, Harper PV, Tovee EB, Woodward ER. Section of the Vagus Nerves to the Stomach in the Treatment of Peptic Ulcer : Complications and End Results After Four Years. Annals of Surgery. 1947; 126(5):687-699.

Dun NJ, Dun SL, Wong PY, Yang J, Chang J. Cocaine- and amphetamine-regulated transcript peptide in the rat epididymis: an immunohistochemical and electrophysiological study. Biology of Reproduction. 2000; 63(5):1518-1524. [PubMed: 11058560]

Dun SL, Castellino SJ, Yang J, Chang JK, Dun NJ. Cocaine- and amphetamine-regulated transcript peptide-immunoreactivity in dorsal motor nucleus of the vagus neurons of immature rats. Brain Research. Developmental Brain Research. 2001; 131(1-2):93-102. [PubMed: 11718840]

Eagleson KL, Lane CJ, McFadyen-Ketchum L, Solak S, Wu HH, Levitt P. Distinct intracellular signaling mediates C-MET regulation of dendritic growth and synaptogenesis. Developmental Neurobiology. 2016a; 76(10):1160-1181. http://doi.org/10.1002/dneu.22382. [PubMed: 26818605]

Eagleson KL, Milner TA, Xie Z, Levitt P. Synaptic and extrasynaptic location of the receptor tyrosine kinase met during postnatal development in the mouse neocortex and hippocampus. The Journal of Comparative Neurology. 2013; 521(14):3241-3259. http://doi.org/10.1002/cne.23343. [PubMed: 23787772] 
Eagleson, KL., Xie, Z., Levitt, P. The Pleiotropic MET Receptor Network: Circuit Development and the Neural-Medical Interface of Autism; Biological Psychiatry. 2016b. p. 1-10.http://doi.org/ 10.1016/j.biopsych.2016.08.035

Ebens A, Brose K, Leonardo ED, Hanson MG, Bladt F, Birchmeier C, et al. Hepatocyte growth factor/ scatter factor is an axonal chemoattractant and a neurotrophic factor for spinal motor neurons. Neuron. 1996; 17(6):1157-1172. [PubMed: 8982163]

Emond A, Emmett P, Steer C, Golding J. Feeding Symptoms, Dietary Patterns, and Growth in Young Children With Autism Spectrum Disorders. Pediatrics. 2010; 126(2):e337-e342. http://doi.org/ 10.1542/peds.2009-2391. [PubMed: 20643716]

Foley JO, DuBois FS. Quantitative studies of the vagus nerve in the cat. I. The ratio of sensory to motor fibers. Journal of Comparative Neurology. 1937

Fox EA, Powley TL. Longitudinal columnar organization within the dorsal motor nucleus represents separate branches of the abdominal vagus. Brain Research. 1985; 341(2):269-282. [PubMed: 4041795]

Furness, JB., Callaghan, BP., Rivera, LR., Cho, H-J. Advances in Experimental Medicine and Biology. Vol. 817. New York, NY: Springer New York; 2014. The Enteric Nervous System and Gastrointestinal Innervation: Integrated Local and Central Control; p. 39-71.http://doi.org/ 10.1007/978-1-4939-0897-4_3

Gautron L, Rutkowski JM, Burton MD, Wei W, Wan Y, Elmquist JK. Neuronal and nonneuronal cholinergic structures in the mouse gastrointestinal tract and spleen. The Journal of Comparative Neurology. 2013; 521(16):3741-3767. http://doi.org/10.1002/cne.23376. [PubMed: 23749724]

German DC, Bruce G, Hersh LB. Immunohistochemical staining of cholinergic neurons in the human brain using a polyclonal antibody to human choline acetyltransferase. Neuroscience Letters. 1985; 61(1-2):1-5. [PubMed: 3908999]

Geschwind D. GENSAT: a genomic resource for neuroscience research. The Lancet. Neurology. 2004; 3(2):82. [PubMed: 14746997]

Gong S, Kus L, Heintz N. Rapid bacterial artificial chromosome modification for large-scale mouse transgenesis. Nature Protocols. 2010; 5(10):1678-1696. http://doi.org/10.1038/nprot.2010.131. [PubMed: 20885380]

Gorrindo P, Williams KC, Lee EB, Walker LS, McGrew SG, Levitt P. Gastrointestinal Dysfunction in Autism: Parental Report, Clinical Evaluation, and Associated Factors. Autism Research. 2012; 5(2):101-108. http://doi.org/10.1002/aur.237. [PubMed: 22511450]

Gutierrez, H., Dolcet, X., Tolcos, M., Davies, A. HGF regulates the development of cortical pyramidal dendrites. Development. 2004. http://doi.org/10.1242/dev.01209

Heuer L, Braunschweig D, Ashwood P, Van de Water J, Campbell DB. Association of a MET genetic variant with autism-associated maternal autoantibodies to fetal brain proteins and cytokine expression. Translational Psychiatry. 2011; 1(10):e48-7. http://doi.org/10.1038/tp.2011.48. [PubMed: 22833194]

Hornby PJ, Rossiter CD, Pineo SV, Norman WP, Friedman EK, Benjamin S, Gillis RA. TRH: immunocytochemical distribution in vagal nuclei of the cat and physiological effects of microinjection. The American Journal of Physiology. 1989; 257(3 Pt 1):G454-62. [PubMed: 2506764]

Ibrahim SH, Voigt RG, Katusic SK, Weaver AL, Barbaresi WJ. Incidence of Gastrointestinal Symptoms in Children With Autism: A Population-Based Study. Pediatrics. 2009; 124(2):680 686. http://doi.org/10.1542/peds.2008-2933. [PubMed: 19651585]

Jacobowitz, DM., Abbott, LC. Chemoarchitectonic Atlas of the Developing Mouse Brain. CRC Press; 1997.

Judson MC, Amaral DG, Levitt P. Conserved Subcortical and Divergent Cortical Expression of Proteins Encoded by Orthologs of the Autism Risk Gene MET. Cerebral Cortex. 2011; 21(7): 1613-1626. http://doi.org/10.1093/cercor/bhq223. [PubMed: 21127014]

Judson MC, Bergman MY, Campbell DB, Eagleson KL, Levitt P. Dynamic gene and protein expression patterns of the autism-associated met receptor tyrosine kinase in the developing mouse forebrain. The Journal of Comparative Neurology. 2009; 513(5):511-531. http://doi.org/10.1002/ cne.21969. [PubMed: 19226509] 
Judson MC, Eagleson KL, Wang L, Levitt P. Evidence of cell-nonautonomous changes in dendrite and dendritic spine morphology in the met-signaling-deficient mouse forebrain. The Journal of Comparative Neurology. 2010; 518(21):4463-4478. http://doi.org/10.1002/cne.22467. [PubMed: 20853516]

Kast RJ, Wu HH, Williams P, Gaspar P, Levitt P. Specific Connectivity and Unique Molecular Identity of MET Receptor Tyrosine Kinase Expressing Serotonergic Neurons in the Caudal Dorsal Raphe Nuclei. ACS Chemical Neuroscience. 2017; 8(5):1053-1064. http://doi.org/10.1021/ acschemneuro.7b00020. [PubMed: 28375615]

Kravitz JJ, Snape WJ, Cohen S. Effect of thoracic vagotomy and vagal stimulation on esophageal function. The American Journal of Physiology. 1978; 234(4):E359-64. [PubMed: 645850]

Krowicki ZK, Burmeister MA, Berthoud HR, Scullion RT, Fuchs K, Hornby PJ. Orexins in rat dorsal motor nucleus of the vagus potently stimulate gastric motor function. AJP: Gastrointestinal and Liver Physiology. 2002; 283(2):G465-G472. http://doi.org/10.1152/ajpgi.00264.2001.

Lambert N, Wermenbol V, Pichon B, Acosta S, van den Ameele J, Perazzolo C, et al. A Familial Heterozygous Null Mutation of MET in Autism Spectrum Disorder. Autism Research. 2014; 7(5): 617-622. http://doi.org/10.1002/aur.1396. [PubMed: 24909855]

Lavenex P, Lavenex PB, Bennett JL, Amaral DG. Postmortem changes in the neuroanatomical characteristics of the primate brain: Hippocampal formation. The Journal of Comparative Neurology. 2009; 512(1):27-51. http://doi.org/10.1002/cne.21906. [PubMed: 18972553]

Lee ZL, Nakayama S. On the gastrocecal inhibitory reflex in the rat. Acta Medica Okayama. 1981; 35(5):357-362. [PubMed: 6458998]

Levy SE, Souders MC, Ittenbach RF, Giarelli E, Mulberg AE, Pinto-Martin JA. Relationship of Dietary Intake to Gastrointestinal Symptoms in Children with Autistic Spectrum Disorders. Biological Psychiatry. 2007; 61(4):492-497. http://doi.org/10.1016/j.biopsych.2006.07.013. [PubMed: 17207470]

Lim CS, Walikonis RS. Hepatocyte growth factor and c-Met promote dendritic maturation during hippocampal neuron differentiation via the Akt pathway. Cellular Signalling. 2008; 20(5):825835. http://doi.org/10.1016/j.cellsig.2007.12.013. [PubMed: 18262389]

Maina F, Hilton MC, Andres R, Wyatt S, Klein R, Davies AM. Multiple roles for hepatocyte growth factor in sympathetic neuron development. Neuron. 1998; 20(5):835-846. [PubMed: 9620689]

Matsubara YEA. Hepatocyte Growth Factor Activator: A Possible Regulator of Morphogenesis during Fetal Development of the Rat Gastrointestinal Tract. 1998:1-8.

McElhanon BO, McCracken C, Karpen S, Sharp WG. Gastrointestinal Symptoms in Autism Spectrum Disorder: A Meta-analysis. Pediatrics. 2014; 133(5):872-883. http://doi.org/10.1542/peds. 2013-3995. [PubMed: 24777214]

Molyneaux BJ, Arlotta P, Fame RM, MacDonald JL, MacQuarrie KL, Macklis JD. Novel SubtypeSpecific Genes Identify Distinct Subpopulations of Callosal Projection Neurons. Journal of Neuroscience. 2009; 29(39):12343-12354. http://doi.org/10.1523/JNEUROSCI.6108-08.2009. [PubMed: 19793993]

Molyneaux BJ, Goff LA, Brettler AC, Chen HH, Brown JR, Hrvatin S, et al. DeCoN: Genome-wide Analysis of In Vivo Transcriptional Dynamics during Pyramidal Neuron Fate Selection in Neocortex. Neuron. 2014; 85(2):275-288. http://doi.org/10.1016/j.neuron.2014.12.024. [PubMed: 25556833]

Monroe MJ, Hornby PJ, Partosoedarso ER. Central vagal stimulation evokes gastric volume changes in mice: a novel technique using a miniaturized barostat. Neurogastroenterology and Motility. 2004; 16(1):5-11. [PubMed: 14764200]

Myers MW, Lazzarini RA, Lee VM, Schlaepfer WW, Nelson DL. The human mid-size neurofilament subunit: a repeated protein sequence and the relationship of its gene to the intermediate filament gene family. The EMBO Journal. 1987; 6(6):1617-1626. [PubMed: 3608989]

Nakamura T, Nishizawa T, Hagiya M, Seki T, Shimonishi M, Sugimura A, et al. Molecular cloning and expression of human hepatocyte growth factor. Nature. 1989; 342(6248):440-443. http://doi.org/ 10.1038/342440a0. [PubMed: 2531289] 
Neuhuber WL, Kressel M, Stark A, Berthoud HR. Vagal efferent and afferent innervation of the rat esophagus as demonstrated by anterograde DiI and DiA tracing: focus on myenteric ganglia. Journal of the Autonomic Nervous System. 1998; 70(1-2):92-102. [PubMed: 9686909]

Northcutt KV, Wang Z, Lonstein JS. Sex and species differences in tyrosine hydroxylase-synthesizing cells of the rodent olfactory extended amygdala. The Journal of Comparative Neurology. 2006; 500(1):103-115. http://doi.org/10.1002/cne.21148.

Okaty BW, Freret ME, Rood BD, Brust RD, Hennessy ML, deBairos D, et al. Multi-Scale Molecular Deconstruction of the Serotonin Neuron System. Neuron. 2015; 88(4):774-791. http://doi.org/ 10.1016/j.neuron.2015.10.007. [PubMed: 26549332]

Park M, Dean M, Cooper CS, Schmidt M, O'Brien SJ, Blair DG, Vande Woude GF. Mechanism of met oncogene activation. Cell. 1986; 45(6):895-904. [PubMed: 2423252]

Parker LM, Kumar NN, Lonergan T, Goodchild AK. Neurochemical codes of sympathetic preganglionic neurons activated by glucoprivation. The Journal of Comparative Neurology. 2013; 521(12):2703-2718. http://doi.org/10.1002/cne.23310. [PubMed: 23348748]

Pascual-Font A, Hernandez-Morato I, McHanwell S, Vázquez T, Maranillo E, Sañudo J, ValderramaCanales FJ. The central projections of the laryngeal nerves in the rat. Journal of Anatomy. 2011; 219(2):217-228. http://doi.org/10.1111/j.1469-7580.2011.01390.x. [PubMed: 21599662]

Paxinos, G. The Rhesus Monkey Brain in Stereotaxic Coordinates. Academic Press; 2009.

Peng Y, Lu Z, Li G, Piechowicz M, Anderson M, Uddin Y, et al. The autism-associated MET receptor tyrosine kinase engagesearly neuronal growth mechanism and controls glutamatergiccircuits development in the forebrain. 2016; 21(7):925-935. http://doi.org/10.1038/mp.2015.182.

Phillips SF, Quigley EM, Kumar D, Kamath PS. Motility of the ileocolonic junction. Gut. 1988; 29(3): 390-406. [PubMed: 3281873]

Plummer JT, Gordon AJ, Levitt P. The Genetic Intersection of Neurodevelopmental Disorders and Shared Medical Comorbidities - Relations that Translate from Bench to Bedside. Frontiers in Psychiatry. 2016; 7(6263):aab3897. http://doi.org/10.1021/cn300186b.

Powley TL, Baronowsky EA, Gilbert JM, Hudson CN, Martin FN, Mason JK, et al. Autonomic Neuroscience: Basic and Clinical. Autonomic Neuroscience : Basic \& Clinical. 2013; 177(2):129_ 142. http://doi.org/10.1016/j.autneu.2013.03.008. [PubMed: 23583280]

Puller C, Manookin MB, Neitz J, Rieke F, Neitz M. Broad Thorny Ganglion Cells: A Candidate for Visual Pursuit Error Signaling in the Primate Retina. Journal of Neuroscience. 2015; 35(13):53975408. http://doi.org/10.1523/JNEUROSCI.4369-14.2015. [PubMed: 25834063]

Qiu S, Lu Z, Levitt P. MET Receptor Tyrosine Kinase Controls Dendritic Complexity, Spine Morphogenesis, and Glutamatergic Synapse Maturation in the Hippocampus. Journal of Neuroscience. 2014; 34(49):16166-16179. http://doi.org/10.1523/JNEUROSCI.2580-14.2014. [PubMed: 25471559]

Rattan S, Goyal RK. Neural Control of the Lower Esophageal Sphincter INFLUENCE OF THE VAGUS NERVES. Journal of Clinical Investigation. 1974; 54(4):899-906. http://doi.org/10.1172/ JCI107829. [PubMed: 4430720]

LGBP, SEA, CC, LSCEO, EWEM, RSM, et al. Food Selectivity in Children with Autism Spectrum Disorders and Typically Developing Children. The Journal of Pediatrics. 2010; 157(2):259-264. http://doi.org/10.1016/j.jpeds.2010.02.013. [PubMed: 20362301]

Renier N, Wu Z, Simon DJ, Yang J, Ariel P, Tessier-Lavigne M. iDISCO: a simple, rapid method to immunolabel large tissue samples for volume imaging. Cell. 2014; 159(4):896-910. http://doi.org/ 10.1016/j.cell.2014.10.010. [PubMed: 25417164]

Rinaman L, Levitt P. Establishment of vagal sensorimotor circuits during fetal development in rats. Journal of Neurobiology. 1993; 24(5):641-659. http://doi.org/10.1002/neu.480240509. [PubMed: 7686963]

Rong S, Bodescot M, Blair D, Dunn J, Nakamura T, Mizuno K, et al. Tumorigenicity of the met protooncogene and the gene for hepatocyte growth factor. Molecular and Cellular Biology. 1992; 12(11):5152-5158. [PubMed: 1406687]

Rubin MR, Cardwell BA, Ouyang A, Snape WJ, Cohen S. Effect of bethanechol or vagal nerve stimulation on ileocecal sphincter pressure in the cat. Ygast. 1981; 80(5 pt 1):974-979. 
Scaal M, Bonafede A, Dathe V, Sachs M, Cann G, Christ B, Brand-Saberi B. SF/HGF is a mediator between limb patterning and muscle development. Development. 1999; 126(21):4885-4893. [PubMed: 10518504]

Schemann M, Grundy D. Electrophysiological identification of vagally innervated enteric neurons in guinea pig stomach. The American Journal of Physiology. 1992; 263(5 Pt 1):G709-18. [PubMed: 1443146]

Schmidt C, Bladt F, Goedecke S, Brinkmann V, Zschiesche W, Sharpe M, et al. Scatter factor/ hepatocyte growth factor is essential for liver development. Nature. 1995; 373(6516):699-702. http://doi.org/10.1038/373699a0. [PubMed: 7854452]

Schwartz TW, Holst JJ, Fahrenkrug J. Vagal, cholinergic regulation of pancreatic polypeptide secretion. Journal of Clinical .... 1978

Sharon G, Sampson TR, Geschwind DH, Mazmanian SK. The Central Nervous System and the Gut Microbiome. Cell. 2016; 167(4):915-932. http://doi.org/10.1016/j.cell.2016.10.027. [PubMed: 27814521]

Shibata S, Miwa T, Wu HH, Levitt P, Ohyama T. Hepatocyte Growth Factor-c-MET Signaling Mediates the Development of Nonsensory Structures of the Mammalian Cochlea and Hearing. Journal of Neuroscience. 2016; 36(31):8200-8209. http://doi.org/10.1523/JNEUROSCI. 4410-15.2016. [PubMed: 27488639]

Shiromani PJ, Armstrong DM, Bruce G, Hersh LB, Groves PM, Gillin JC. Relation of pontine choline acetyltransferase immunoreactive neurons with cells which increase discharge during REM sleep. Brain Research Bulletin. 1987; 18(3):447-455. [PubMed: 3580914]

Sonnenberg E, Meyer D, Weidner KM, Birchmeier C. Scatter factor/hepatocyte growth factor and its receptor, the c-met tyrosine kinase, can mediate a signal exchange between mesenchyme and epithelia during mouse development. The Journal of Cell Biology. 1993; 123(1):223-235. [PubMed: 8408200]

Sousa I, Clark TG, Toma C, Kobayashi K, Choma M, Holt R, et al. MET and autism susceptibility: family and case-control studies. European Journal of Human Genetics : EJHG. 2009; 17(6):749758. http://doi.org/10.1038/ejhg.2008.215. [PubMed: 19002214]

Stoker M, Gherardi E, Perryman M, Gray J. Scatter factor is a fibroblast-derived modulator of epithelial cell mobility. Nature. 1987; 327(6119):239-242. http://doi.org/10.1038/327239a0. [PubMed: 2952888]

Thanseem I, Nakamura K, Miyachi T, Toyota T, Yamada S, Tsujii M, et al. Neuroscience Research. Neuroscience Research. 2010; 68(2):137-141. http://doi.org/10.1016/j.neures.2010.06.014. [PubMed: 20615438]

Tong WD, Ridolfi TJ, Kosinski L, Ludwig K, Takahashi T. Effects of autonomic nerve stimulation on colorectal motility in rats. Neurogastroenterology and Motility. 2010; 22(6):688-693. http:// doi.org/10.1111/j.1365-2982.2009.01461.x. [PubMed: 20067587]

Valicenti-McDermott M, McVicar K, Rapin I, Wershil BK, Cohen H, Shinnar S. Frequency of gastrointestinal symptoms in children with autistic spectrum disorders and association with family history of autoimmune disease. Journal of Developmental and Behavioral Pediatrics : JDBP. 2006; 27(2 Suppl):S128-36. [PubMed: 16685179]

Voineagu I, Wang X, Johnston P, Lowe JK, Tian Y, Horvath S, et al. Transcriptomic analysis of autistic brain reveals convergent molecular pathology. Nature. 2011; 474(7351):380-384. http://doi.org/ 10.1038/nature10110. [PubMed: 21614001]

Wu HH, Levitt P. Prenatal Expression of MET Receptor Tyrosine Kinase in the Fetal Mouse Dorsal Raphe Nuclei and the Visceral Motor/Sensory Brainstem. Developmental Neuroscience. 2013; 35(1):1-16. http://doi.org/10.1159/000346367. [PubMed: 23548689]

Wu HH, Bellmunt E, Scheib JL, Venegas V, Burkert C, Reichardt LF, et al. Glial precursors clear sensory neuron corpses during development via Jedi-1, an engulfment receptor. Nature Neuroscience. 2009; 12(12):1534-1541. http://doi.org/10.1038/nn.2446. [PubMed: 19915564]

Wylie CJ, Hendricks TJ, Zhang B, Wang L, Lu P, Leahy P, et al. Distinct Transcriptomes Define Rostral and Caudal Serotonin Neurons. Journal of Neuroscience. 2010; 30(2):670-684. http:// doi.org/10.1523/JNEUROSCI.4656-09.2010. [PubMed: 20071532] 
Xie, Z., Eagleson, KL., Wu, HH., Levitt, P. Hepatocyte Growth Factor modulates MET receptor tyrosine kinase and -catenin functional interactions to enhance synapse formation. eNeuro. 2016. http://doi.org/10.1523/ENEURO.0074-16.2016

Yamamoto K, Ruuskanen JO, Wullimann MF, Vernier P. Molecular and Cellular Neuroscience. Molecular and Cellular Neuroscience. 2010; 43(4):394-402. http://doi.org/10.1016/j.mcn. 2010.01.006. [PubMed: 20123022]

Yang H, Ohning G, Taché Y. TRH in dorsal vagal complex mediates acid response to excitation of raphe pallidus neurons in rats. The American Journal of Physiology. 1993; 265(5 Pt 1):G880-6. [PubMed: 8238517]

Yang Y, Spitzer E, Meyer D, Sachs M. Sequential requirement of hepatocyte growth factor and neuregulin in the morphogenesis and differentiation of the mammary gland. The Journal of Cell .... 1995

Zhou SY, Lu YX, Yao H, Owyang C. Spatial organization of neurons in the dorsal motor nucleus of the vagus synapsing with intragastric cholinergic and nitric oxide/VIP neurons in the rat. American Journal of Physiology. Gastrointestinal and Liver Physiology. 2008; 294(5):G1201G1209. http://doi.org/10.1152/ajpgi.00309.2006. [PubMed: 18460697] 

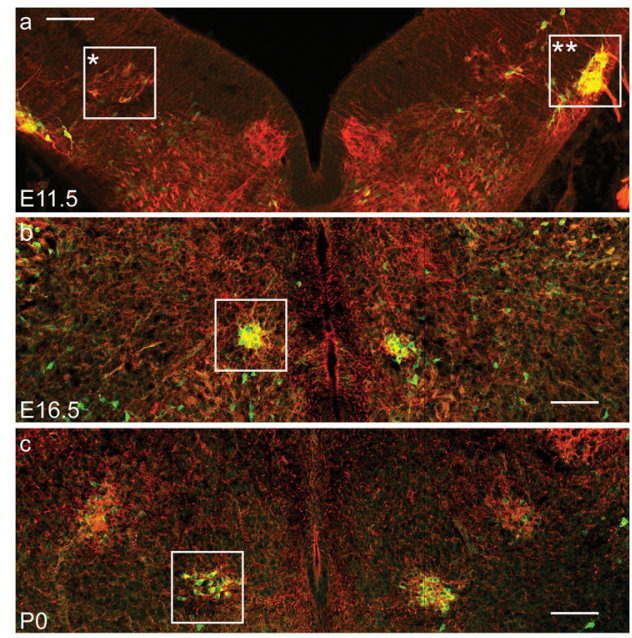

롤
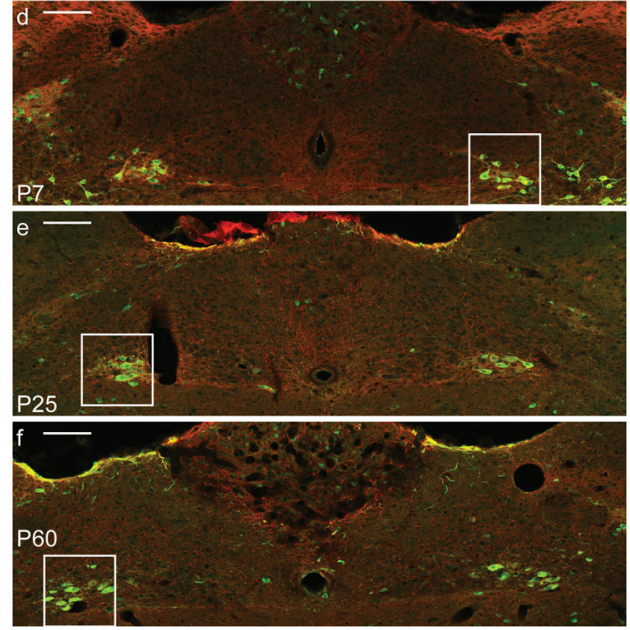

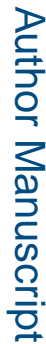

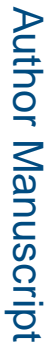



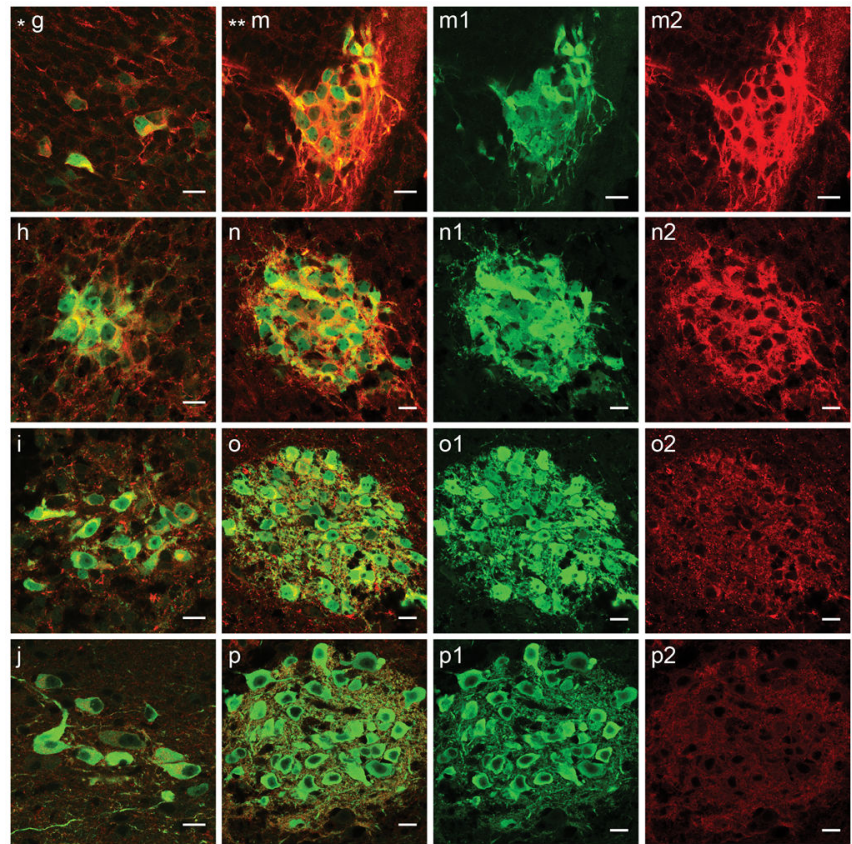

p2
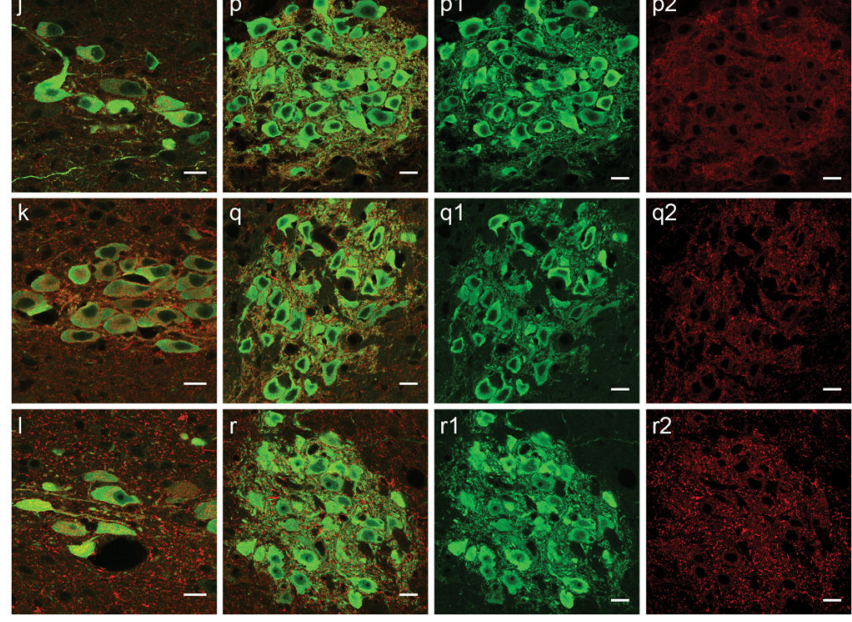

Figure 1.

Ontogenesis of MET expression in brainstem vagal motor neurons. MET (red) and EGFP+ (green) immunofluorescent labeling is illustrated in coronal sections of the brainstem from $\mathrm{Met}^{\mathrm{EGFP}}$ mice at 6 ages. White boxes indicate the areas imaged at higher magnification in $\mathrm{g}$ 1. Asterisks indicate the presumptive DMV (*) and nAmb (**) prior to the establishment of clear cytological boundaries for these nuclei. Single channel images of EGFP (m1-r1) and MET (m2-r2) immunoreactivity in the nAmb are shown. Note the readily detected doublelabeled somata and processes at embryonic ages. EGFP brightness and contrast in postnatal samples has been globally increased in images to illustrate cell morphology. Scale bars in a$\mathrm{f}=100 \mu \mathrm{m}$. Scale bars in $\mathrm{g}-\mathrm{r}=15 \mu \mathrm{m}$. 

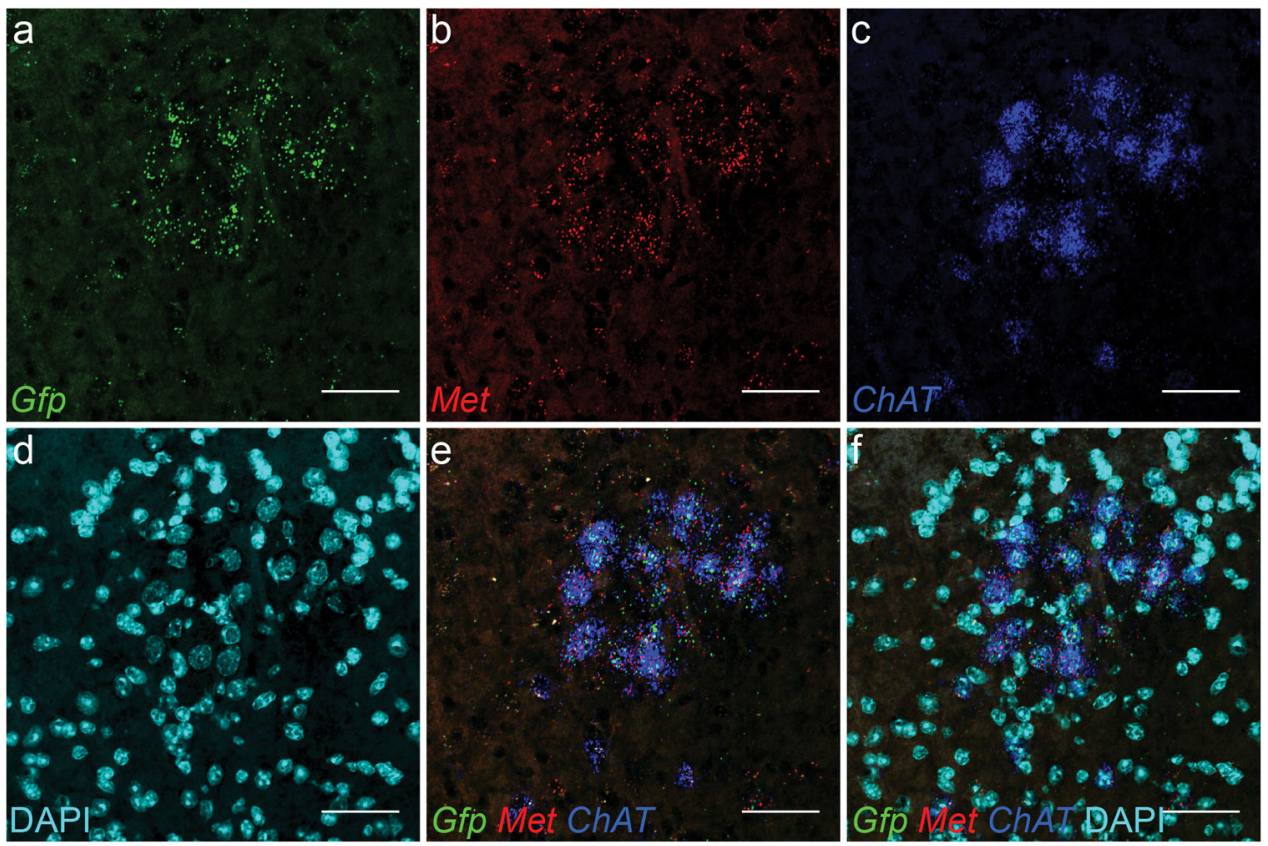

Figure 2.

There is high fidelity co-expression of Gfp and Met mRNA in vagal motor neurons of $\mathrm{Met}^{\mathrm{EGFP}}$ reporter mice. Multiplex fluorescent in situ hybridization (FISH) using RNAscope probes for $G f p$ (a), Met (b), and Chat (c) in coronal sections through the nAmb of a Met ${ }^{\text {EGFP }}$ mouse at P60. DAPI-labeled nuclei are shown in (d). e and f illustrate merged images of FISH signal from each probe without (e), and with DAPI labeled nuclei (f). Scale bars in a-f $=50 \mu \mathrm{m}$. 

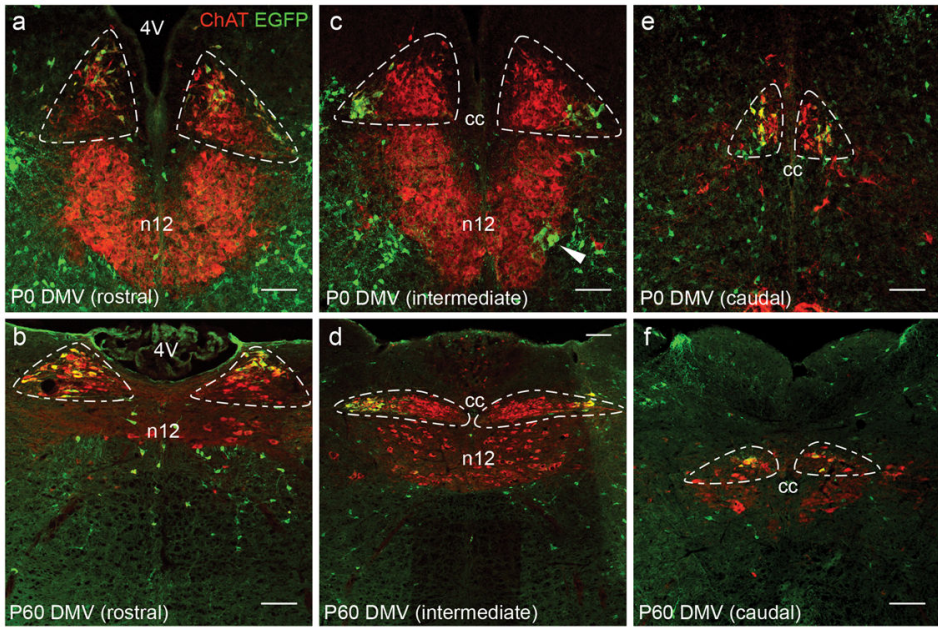

9

PO nAmb (sagittal)
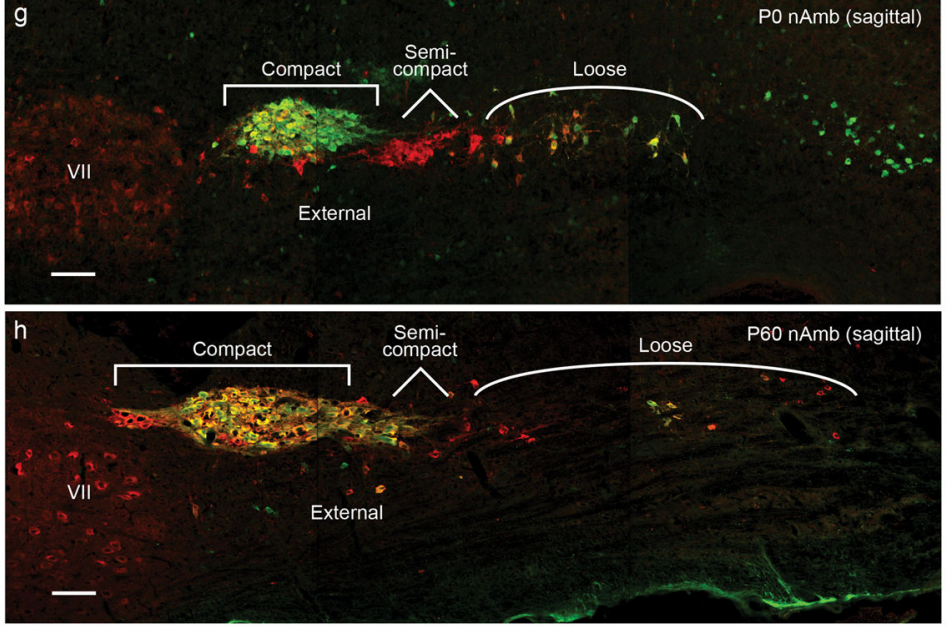

Figure 3.

Distribution of EGFP+ cells that comprise subpopulations of vagal motor neurons. ChAT (red) and EGFP+ (green) immunofluorescent labeling of coronal brainstem sections through the caudal medulla of Met ${ }^{\mathrm{EGFP}}$ mice are illustrated at P0 and P60 (a-f). Images are from rostral $(a, b)$, intermediate (c, d), and caudal $(e, f)$ coronal levels of the DMV. Dashed lines indicate the cytological boundaries of the DMV. Arrowhead indicates EGFP+ neurons in n12. $4 \mathrm{~V}$, fourth ventricle. cc, central canal. n12, hypoglossal nucleus. ChAT and EGFP immunofluorescent labeling of sagittal brainstem sections is shown in $\mathrm{g}-\mathrm{h}$. Images depict the subregions of the nAmb of Met ${ }^{\mathrm{EGFP}}$ mice at ages P0 and P60. These subregions of the nAmb include the compact, semicompact, loose, and external formations. VII, facial motor nucleus. All scale bars $=100 \mu \mathrm{m}$. 


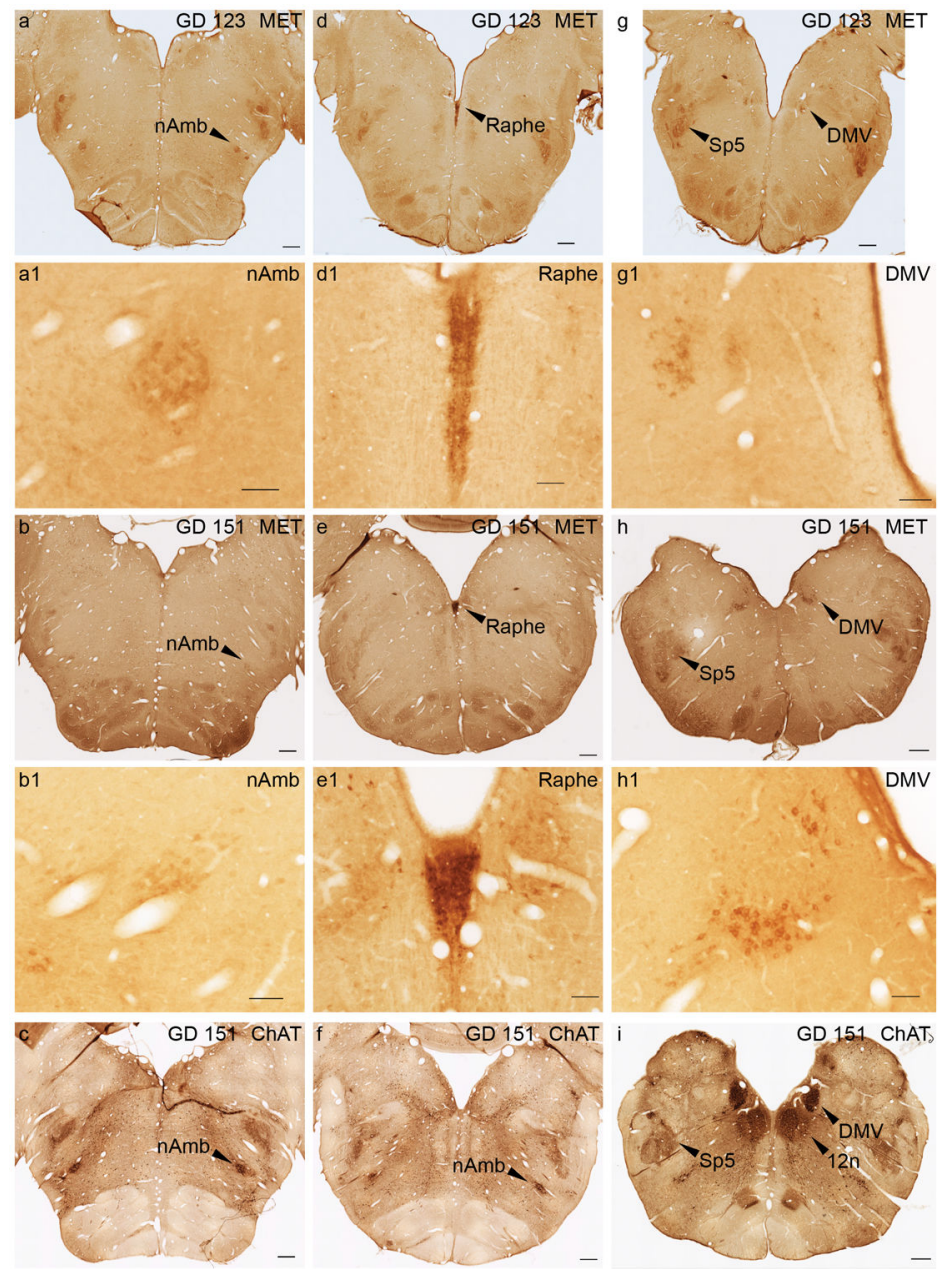

Figure 4.

Rostral-caudal distribution of MET+ brainstem vagal motor neurons in the developing rhesus macaque. MET (a, b, d, e, g, h) and $\operatorname{ChAT~(c,~f,~i)~immunocytochemical~labeling~in~}$ coronal brainstem sections from rhesus macaques aged gestational day 123 and 151 . Higher magnification images of MET immunolabeled sections are shown and denoted by the matching letter and the number ' 1 '. Sp5, spinal trigeminal nucleus. $12 \mathrm{n}$, twelfth cranial nucleus. Scale bars in $\mathrm{a}-\mathrm{i}=1 \mathrm{~mm}$. Scale bars in $\mathrm{a} 1-\mathrm{h} 1=100 \mu \mathrm{m}$. 

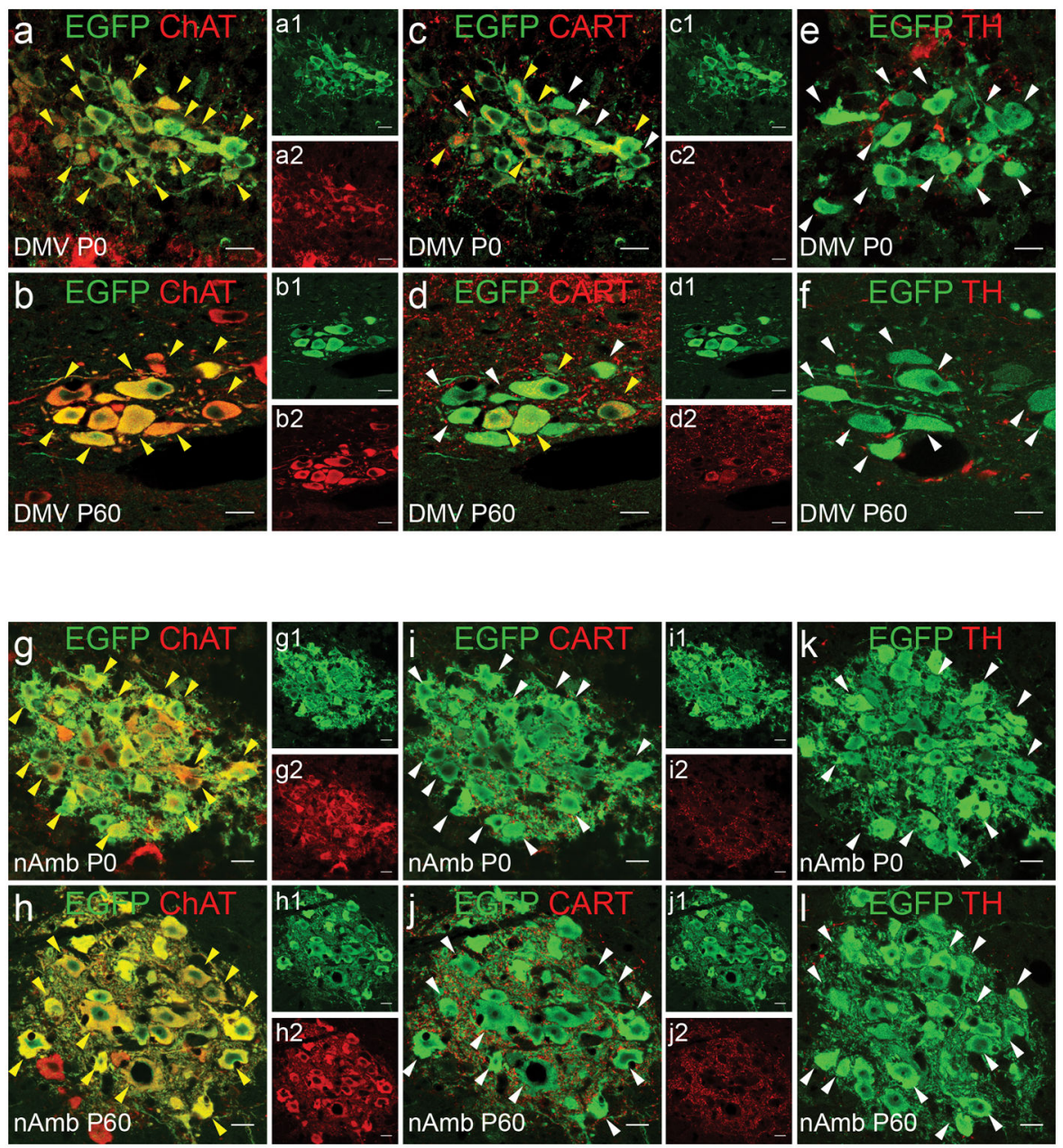

Figure 5.

Neurotransmitter and neuropeptide phenotypes of EGFP+ neurons in the DMV and nAmb. EGFP+ (green) fluorescent labeling is shown in the DMV (a-f) and compact formation of the nAmb (g-l) at P0 (a, c, e, g, i, and k) and P60 (b, d, f, h, j, and l). Single channel images of EGFP (a1-j1), ChAT (a2, b2, g2, and h2), and CART (c2, d2, i2, and j2) are shown. Subsets of co-labeled neurons that express ChAT or CART are evident, whereas none were visualized that co-express EGFP and TH (red). ChAT, CART, and EGFP immunolabeling was performed on the same set of tissue sections, at each age. A second set of tissue sections was used to co-label TH and EGFP at each age. Scale bars $=15 \mu \mathrm{m}$. 

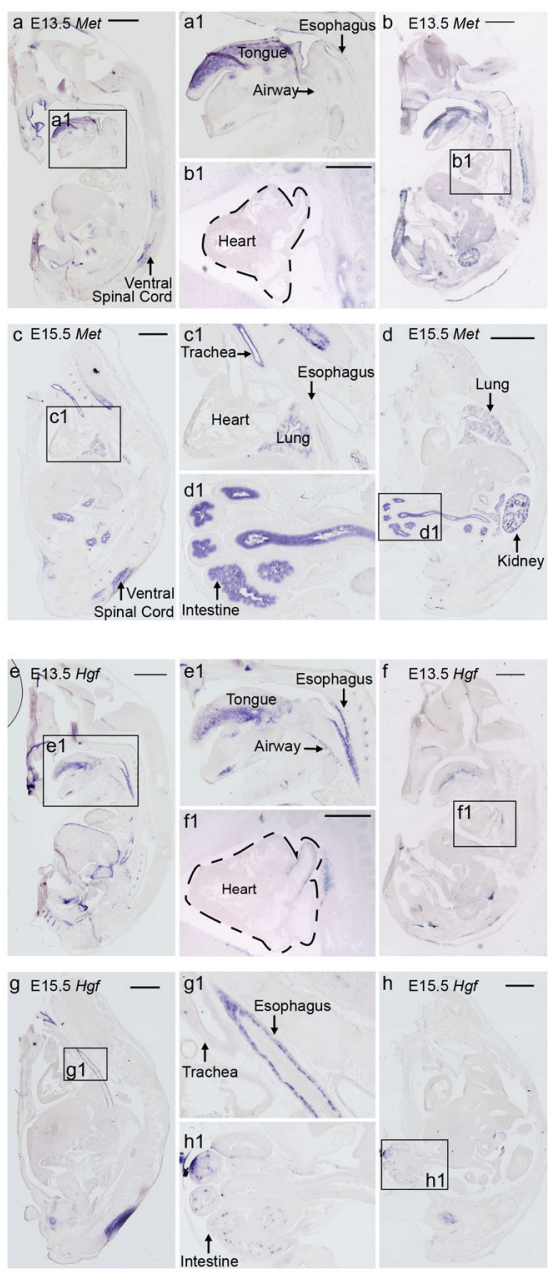

Figure 6.

In situ hybridization for Met and $\mathrm{Hgf}$ mRNA in the fetal mouse. Hybridized riboprobe labeling for Met $(\mathrm{a}-\mathrm{d})$ or $\mathrm{Hgf}(\mathrm{e}-\mathrm{h})$ mRNA in sagittal sections from mouse embryos on E13.5 and E15.5 provide evidence for complimentary expression patterns in the periphery. Boxes indicate the areas enlarged and denoted by the matching letter and the number ' 1 '. Scale bars in a, b, c, d, e, f, g, and h $=1 \mathrm{~mm}$. Scale bars in b1 and $\mathrm{f} 1=500 \mu \mathrm{m}$. 

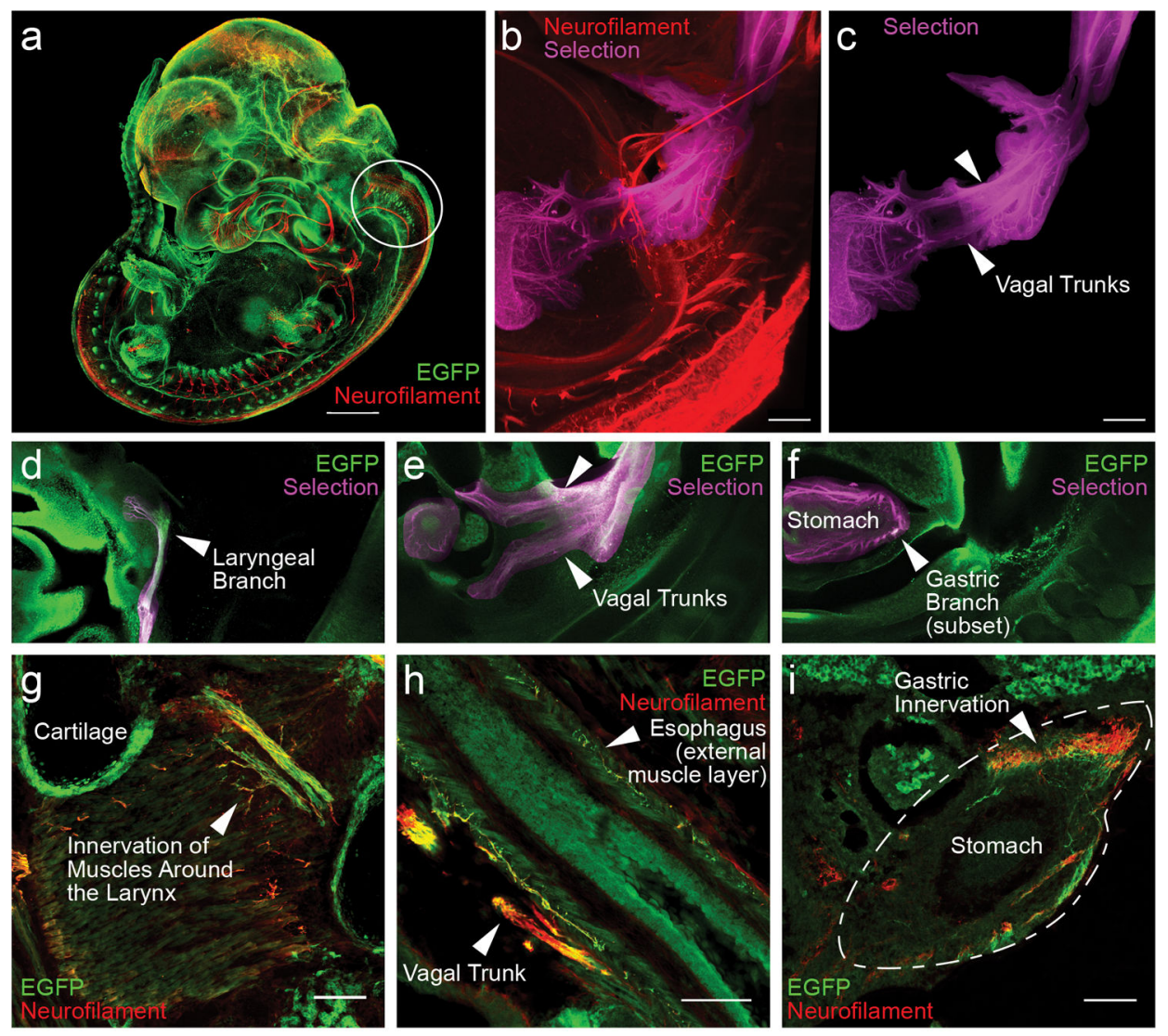

Figure 7.

Innervation targets of brainstem vagal MET neurons in the developing mouse. (a) Wholemount iDISCO staining and tissue clearing in a Met ${ }^{\text {EGFP }}$ mouse embryo at E11.5. EGFP+ (green) and neurofilament (red) fluorescent labeling are used to identify METexpressing neurons in the brainstem and their axonal trajectories to presumptive innervation sites in the periphery. Circle indicates the location of brainstem vagal motor neurons expressing MET. (b and c) Following wholemount iDISCO staining and tissue clearing in a $\mathrm{Met}^{\mathrm{EGFP}}$ mouse at E13.5, Imaris-assisted selection of neurofilament labeling corresponding to the vagus was manually identified as the nerves emerge from the brainstem, and the trajectory of the vagal trunks was followed to innervation targets. Neurofilament labeling is shown in red, and the Imaris-assisted selection of vagal nerves is shown in magenta. (d, e, and f) Single image planes from wholemount Met ${ }^{\text {EGFP }}$ mouse at E13.5, illustrating EGFP immunoreactivity colocalized to the Imaris-assisted selection of vagal nerves. EGFP+ axons were identified in the laryngeal branch of the vagus, in the main vagal trunks and small branches as they descend along the esophagus, and in a subset of gastric branches around the stomach. Tissue sections from perinatal Met ${ }^{\mathrm{EGFP}}$ mice illustrate EGFP (green) immunoreativity colocalized to neurofilament (red) in $\mathrm{g}$, h, and i. Colocalized areas included laryngeal branches of the vagus (g, P0), vagal trunks (h, E16.5), and axonal fibers within the external muscle layer of the esophagus (h, E16.5) and stomach (i, E13.5). Scale bar in a = $500 \mu \mathrm{m}$. Scale bars in $\mathrm{b}$ and $\mathrm{c}=200 \mu \mathrm{m}$. Scale bars in $\mathrm{g}, \mathrm{h}$, and $\mathrm{i}=100 \mu \mathrm{m}$. 


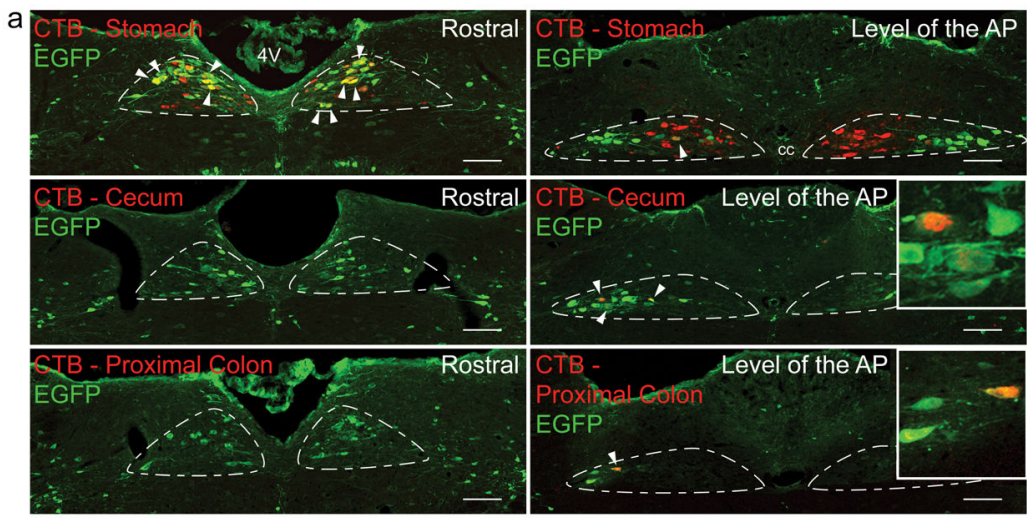

b

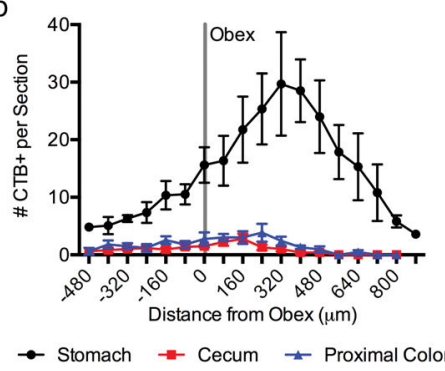

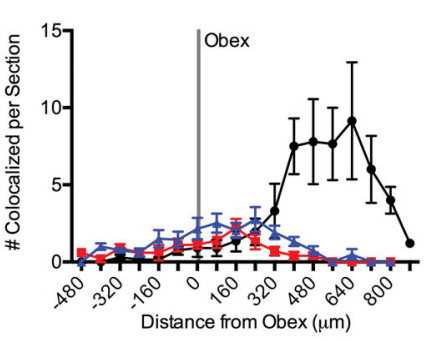

- Stomach $\rightarrow$ Cecum $₫$ Proximal Colon

d
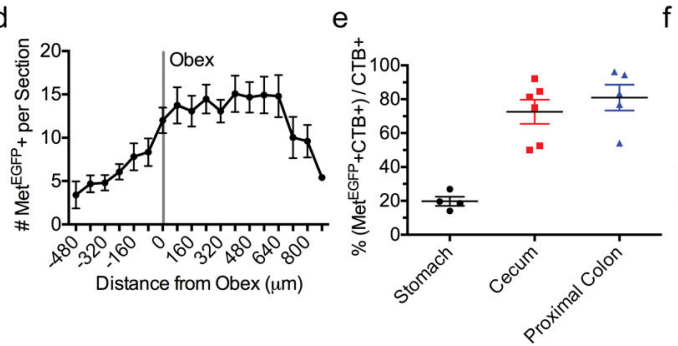

$f$

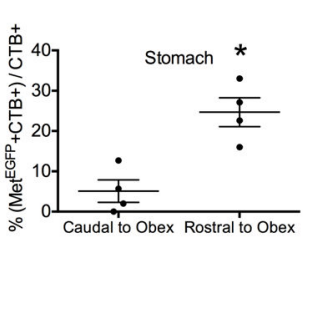

Figure 8.

Vagal EGFP+ motor neurons project to the stomach, cecum, and proximal colon. (a) Representative images illustrating the distribution of EGFP+ (green) and CTB+ (red) somata following retrograde injection of CTB into the stomach, cecum, or proximal colon. Coronal sections from a rostral level of the DMV, and sections at the level of the area postrema (AP) illustrate the rostral-caudal differences in EGFP+ neuron colocalization with CTB. Insets are enlarged areas of the same section highlighting colocalized neurons. (b) The mean number of labeled $\mathrm{CTB}+$ neurons per section is plotted for each injection site. Across all injection cases, sections were aligned anatomically in relation to distance from the obex. (c) The mean number of EGFP+ neurons colocalized with CTB per section is plotted along the rostralcaudal axis in relation to the obex. (d) The mean number of EGFP+ neurons is plotted along the rostral-caudal axis in relation to the obex $(\mathrm{n}=9$ mice). (e) The percentage of CTB+ neurons colocalized with MET ${ }^{\text {EGFP }}$ is plotted. (f) Of CTB injections into the stomach, the percentage of $\mathrm{CTB}+$ neurons colocalized with EGFP is subdivided into those rostral or caudal to the obex. Scale bars in a $=100 \mu \mathrm{m}$. Dashed lines indicate the cytological boundaries of the DMV. Arrow heads indicate example colocalized neurons. $4 \mathrm{~V}$, fourth 
ventricle. $\mathrm{cc}$, central canal. Stomach, $\mathrm{n}=4$. Cecum, $\mathrm{n}=6$. Proximal colon, $\mathrm{n}=5 . *$ denotes $\mathrm{p}<0.05$. 


\section{Table 1}

Primary Antibody Table

\begin{tabular}{|c|c|c|c|}
\hline Antibody & Immunogen & $\begin{array}{l}\text { Manufacturer, Calalog \#, } \\
\text { RRID, Host Species, } \\
\text { Monoclonal/Polyclonal }\end{array}$ & Concentration Used \\
\hline $\begin{array}{l}\text { 1. Cocaine- and } \\
\text { amphetamine-regulated } \\
\text { transcript(CART), 55-102 }\end{array}$ & $\begin{array}{l}\text { Ile - Pro - Ile - Tyr - Glu - Lys - Lys - Tyr - Gly - } \\
\text { Gln - Val - Pro - Met - Cys - Asp - Ala - Gly - Glu } \\
\text { - Gln - Cys - Ala - Val - Arg - Lys - Gly - Ala - } \\
\text { Arg - Ile - Gly - Lys - Leu - Cys - Asp - Cys - Pro } \\
\text { - Arg - Gly - Thr - Ser - Cys - Asn - Ser - Phe - } \\
\text { Leu - Leu - Lys - Cys - Leu [Disulfide bonds } \\
\text { between Cys } 1 \text { - Cys 3, Cys 2 - Cys 5, Cys } 4 \text { - Cys } \\
\text { 6] }\end{array}$ & $\begin{array}{l}\text { Phoenix Pharmaceuticals, } \\
\text { H-003-62, RRID:AB_2313614, } \\
\text { Rabbit, Polyclonal }\end{array}$ & $1: 10,000$ \\
\hline $\begin{array}{l}\text { 2. Choline } \\
\text { Acetyltransferase (ChAT) }\end{array}$ & Purified human placental ChAT enzyme & $\begin{array}{l}\text { Millipore, AB144P, } \\
\text { RRID:AB_2079751, Goat, } \\
\text { Polyclonal }\end{array}$ & $1: 500$ \\
\hline $\begin{array}{l}\text { 3. Green Fluorescent } \\
\text { Protein (GFP) }\end{array}$ & $\begin{array}{l}\text { Recombinant full length protein corresponding to } \\
\text { GFP }\end{array}$ & $\begin{array}{l}\text { Abcam, ab13970, } \\
\text { RRID:AB_300798, Chicken, } \\
\text { Polyclonal }\end{array}$ & $1: 500$ \\
\hline $\begin{array}{l}\text { 4. Green Fluorescent } \\
\text { Protein (GFP) }\end{array}$ & GFP emulsified in Freund's adjuvant & $\begin{array}{l}\text { Aves Labs, GFP-1020, } \\
\text { RRID:AB_10000240, Chicken, } \\
\text { Polyclonal }\end{array}$ & $1: 400$ \\
\hline $\begin{array}{l}\text { 5. MET receptor tyrosine } \\
\text { kinase (MET), Clone } \\
25 \mathrm{H} 2\end{array}$ & $\begin{array}{l}\text { Synthetic peptide containing amino acid residues } \\
1228-1243 \text { of human Met c-terminus }\end{array}$ & $\begin{array}{l}\text { Cell Signaling Technology, } \\
\text { 3127, RRID:AB_331361, } \\
\text { Mouse, Monoclonal }\end{array}$ & $1: 400$ \\
\hline $\begin{array}{l}\text { 6. MET receptor tyrosine } \\
\text { kinase (MET/HGF-R) }\end{array}$ & Recombinant mouse Met, Glu25-Asn929 & $\begin{array}{l}\text { R and D Systems, AF527, } \\
\text { RRID:AB_355414, goat, } \\
\text { Polyclonal }\end{array}$ & $1: 500$ \\
\hline 7. Neurofilament & E14-E15 rat spinal cord & $\begin{array}{l}\text { Developmental Studies } \\
\text { Hybridoma Bank (DSHB), 2H3- } \\
\text { c, RRID:AB_531793, Mouse, } \\
\text { Monoclonal }\end{array}$ & $\begin{array}{l}1: 1,000 \text { for tissue } \\
\text { sections, } 1: 500 \text { for } \\
\text { whole mount }\end{array}$ \\
\hline $\begin{array}{l}\text { 8. Tyrosine Hydroxylase } \\
\text { (TH) }\end{array}$ & $\begin{array}{l}\text { Sodium dodecyl sulfate denatured tyrosine } \\
\text { hydroxylase from rat pheochromocytoma }\end{array}$ & $\begin{array}{l}\text { Millipore, AB152, } \\
\text { RRID:AB_390204, Rabbit, } \\
\text { Polyclonal }\end{array}$ & $1: 1,000$ \\
\hline
\end{tabular}

